\title{
Recent Advances and an Industrial Perspective of Cellulose Nanocrystal Functionalization through Polymer Grafting
}

\author{
Stephanie A. Kedzior ${ }^{\mathrm{a}}$, Justin O. Zoppe ${ }^{\mathrm{b}}$, Richard M. Berry ${ }^{\mathrm{c}}$, Emily D. Cranston ${ }^{\mathrm{d}, *}$ \\ aDepartment of Chemical and Petroleum Engineering, University of Calgary, 2500 University \\ Drive NW, Calgary, AB, Canada, T2N 1N4 \\ ${ }^{b}$ Adolphe Merkle Institute, University of Fribourg, Chemin des Verdiers 4, CH-1700 Fribourg, \\ Switzerland \\ ${ }^{c}$ CelluForce Inc., 625 Président-Kennedy Avenue, Montreal, QC, Canada, H3A 1K2 \\ ${ }^{\mathrm{d}}$ Department of Chemical Engineering, McMaster University, 1280 Main Street West, Hamilton, \\ ON, Canada, L8S 4L7 \\ *Corresponding author: Dr. Emily D. Cranston, ecranst@ mcmaster.ca
}

\begin{abstract}
Cellulose nanocrystals (CNCs) are an emerging nanomaterial for applications ranging from coatings and construction to adhesives and biomedical devices. Owing to their high aspect ratio, stiffness, and reinforcing potential, CNCs have shown great promise to be used in polymer nanocomposites. However, due to their inherent hydrophilicity and compatibility with polar environments, the use of CNCs in hydrophobic polymer matrices or in organic solvent-based formulations has been limited. To overcome this incompatibility, many reports on grafting polymers onto the surface of CNCs have been published over the past ten years. This review describes the recent advances in CNC surface functionalization through polymer grafting, and comprehensively covers the existing work to date. Methods including polymer "grafting to" and "grafting from" are described in detail, using polymerization techniques such as free radical, ring opening, and controlled radical polymerization. Purification and characterization of polymergrafted $\mathrm{CNCs}$, the potential for upscaling these functionalization methods, and current perspectives from academic and industrial viewpoints are presented.
\end{abstract}

Keywords: cellulose nanocrystals; polymer grafting; surface functionalization; grafting to; grafting from; free radical polymerization; ring opening polymerization; controlled radical polymerization; manufacturing considerations; patents 


\section{Introduction}

Since the 12 principles of green chemistry were first proposed by Anastas and Warner in the late 1990s [1], there has been a significant shift towards the use of sustainable materials to replace toxic and petroleum-derived chemicals. Nanoparticles from renewable resources, such as cellulose nanocrystals $(\mathrm{CNCs})$ have the potential to address several of the 12 principles, while additionally imparting new properties and functionality to existing materials. CNCs were first reported by Nickerson and Habrle in 1947 [2], but the widespread interest in their use was spurred by a series of papers published by Derek Gray and coworkers in the 1990s that focused on the physicochemical properties of $\mathrm{CNCs}$ [3-5], as well as the first reports on using CNCs in nanocomposites, published in 1995 [6]. CNCs are rigid, rod-shaped nanoparticles derived from natural cellulose sources, most commonly wood pulp and cotton [7]. This unique nanomaterial has piqued the interest of many researchers, and a number of comprehensive review articles describe their structure [8,9], properties [7,10-12], and potential applications [11,13-16].

CNCs differ from other types of cellulose nanomaterials due to their higher degree of crystallinity (leading to higher stiffness and strength) and smaller size, making them a true nanomaterial in all dimensions. The term "cellulose nanomaterials" is often used, along with "nanocellulose", to define a wide variety of nanoscale cellulosic (or lignocellulosic) materials including cellulose nanofibrils (CNFs), bacterial nanocellulose (BNC), and CNCs [16]. All types of cellulose nanomaterials are fibre, ribbon or rod-like with a range of lengths and widths depending on the isolation method and the starting cellulose source. CNFs are produced primarily through the mechanical disintegration of plant fibers, BNC is produced via a "bottom up" approach by particular genera of bacteria, while CNCs may be produced from many sources (such as plants, BNC, tunicate and algae) via chemical methods [17]. While a number of valuable contributions have been achieved in the case of surface modification of CNFs and BNC via polymer grafting [18-23], this review highlights recent advances focused on polymer grafting with CNCs, including tables that comprehensively summarize all reports on the preparation of polymer-grafted $\mathrm{CNCs}$ to date.

CNCs are typically isolated using a sulfuric acid hydrolysis process that preferentially degrades the disordered cellulose regions, yielding nanoparticles with high crystallinity and uniformity [17]. Sulfuric acid hydrolysis results in sulfate half-ester groups grafted to the CNC surface, which 
impart anionic surface charges. CNCs can also be prepared with hydrochloric acid, which gives uncharged nanoparticles, or through oxidation methods that produce CNCs with surface carboxylic acid moieties [24,25]. The abundance of hydroxyl groups in the cellulose chains means that CNCs are generally considered hydrophilic. However, the packing of cellulose chains within individual CNC particles results in a hydrophobic crystal plane "edge" [26] which leads to amphiphilic properties (that are dependent on the CNC surface charge and isolation method) such that CNCs have been shown to stabilize a variety of emulsions and foams [27].

The colloidal stability of sulfated CNCs (called "unmodified CNCs" herein) in aqueous dispersions has been extensively studied [28], and it is well known that CNCs form stable suspensions in water. These suspensions remain stable over a large range of $\mathrm{pH}$ values (if the ionic strength remains below about $50 \mathrm{mM}$ [29]), i.e., from approximately pH 3 to 11. Still, highly acidic conditions are known to destabilize the suspensions due to the protonation of acid groups [30] and further acid-catalyzed hydrolysis of the CNCs [31]. Extreme alkaline conditions are also known to destabilize CNC suspensions as basic conditions can be used to de-sulfate CNCs [32]. Furthermore, CNC colloidal stability has been studied in organic solvents, with dimethyl sulfoxide (DMSO), dimethylformamide (DMF), formic acid and polar organic solvents showing the best ability to disperse CNCs [33-35]. Other organic solvents, such as ethanol, toluene, chloroform etc. are poor dispersing media for CNCs and lead to severe aggregation, meaning that processing or functionalizing CNCs in these solvents will not provide uniform materials. However, if hydrogen bonding between CNCs and solvents are maintained via solvent exchange approaches, CNCs can be introduced into a wider variety of solvents. This process is nevertheless time consuming and typically involves centrifugation steps, which may lead to some degree of CNC aggregation. The limitation of preparing well-dispersed CNC suspensions in organic solvents can be also overcome via polymer grafting, which allows for the modification of CNCs with hydrophobic polymers in order to improve their compatibility with non-polar media and/or induce steric stabilization $[8,36,37]$

With the goal of using CNCs in commercial and high volume applications, CNC production has been scaled up and the hydrolysis and purification have been optimized using a variety of cellulosic feedstocks. CelluForce Inc, located in Windsor, Quebec, Canada currently operates the largest production facility with the capacity to produce ton per day quantities of CNCs via the sulfuric 
acid hydrolysis of bleached Kraft pulp. Alberta Innovates Technology Futures (recently renamed InnoTech Alberta), and the USDA Forest Products Lab are also producing CNCs at a kg per day capacity and tens of kg per day, respectively, using dissolving wood pulp. These CNCs have properties comparable to those made via lab scale processes [38]. With an expanding variety of producers and cellulose sources, there is a large potential for CNCs to be used in exciting industrially-relevant applications such as packaging, coatings, adhesives, construction materials, biomedical devices [39], and even high volume oil and gas extraction fluids [40].

For many of the envisioned applications, CNCs need to function in hydrophobic polymers, organic solvents, or high salt (e.g., brine) conditions, which require CNC surface modification. A number of reports on CNC surface modifications have been published and patented in recent years [8]. Aside from polymer grafting, which is the focus of this review, other common surface modification routes include non-covalent surface modifications (i.e., adsorption of polymers or surfactants [4146]) and small molecule covalent surface modifications such as esterification, etherification, silylation, amidation and urethanization [8].

Polymer grafting serves to covalently attach polymer chains to CNCs to give brush or mushroomlike surface morphologies following two methods: "grafting to" where pre-formed polymer is attached to the surface of the CNCs, or "grafting from" where the polymerization is initiated from the CNC surface (Figure 1). Polymer grafting to is beneficial since the polymer can be carefully synthesized and thoroughly characterized before it is grafted to the CNCs and reactions are often carried out in water. However, theoretically steric hindrance limits the density of polymers that can be grafted to a single nanoparticle, and most reports of grafting to CNCs do not report a value for polymer graft density. If a graft density is reported, it is typically on the low end compared to the range reported for grafting from CNCs via ATRP. Grafting from generally allows for a higher grafting density, as many initiating sites are available on the CNC surface, but the method tends to be multi-step and characterizing the polymer chain length and polymerization kinetics can be challenging [47]. 


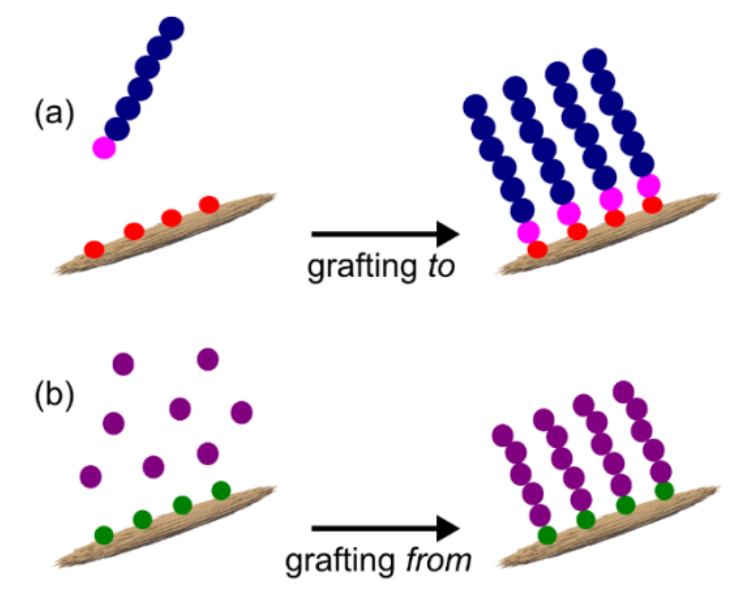

Figure 1. Schematic of (a) grafting to $\mathrm{CNCs}$ with a given $\mathrm{CNC}$ reactive group (red) and a preformed polymer (blue) that is end functionalized (pink) and (b) grafting from CNCs with inherent (surface hydroxyl groups) or added initiating groups (green). Individual purple circles represent monomers and chains of circles are polymers.

In this review, we aim to provide a comprehensive report of the published work involving polymer grafting to and from $\mathrm{CNCs}$, while specifically highlighting recent advances and the outlook for scale-up and industrial feasibility. The review is arranged by type of polymer grafting, and should provide the reader with a general understanding of polymer-grafted CNC synthesis and the reported examples to date.

\section{Polymer grafting to CNCs}

The grafting to method generally takes advantage of the abundance of reactive hydroxyl groups on the $\mathrm{CNC}$ surface and end-functionalized polymers. The main benefit of grafting to is the fact that the grafted polymers can be characterized prior to their attachment to CNCs, allowing for a known polymer graft length. However, grafting to can be limited due to steric hindrance, as long chain polymers may entangle with one another or hinder the diffusion of subsequent polymer chain ends to reach the $\mathrm{CNC}$ surface. In cases such as the work by Araki et al.[48], polymer grafting to CNCs was used to impart steric as opposed to electrostatic stabilization. This pioneering work was a seminal contribution to the field of polymer-grafted CNCs. Table 1 summarizes all existing literature using grafting to to modify CNCs with polymers, with the most common chemistry being carbodiimide coupling, epoxy ring opening, and isocyanate-mediated grafting, shown in Figure 2. 
(a)

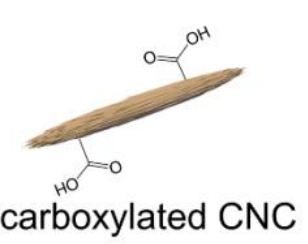

(b)

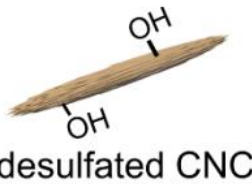

(c)

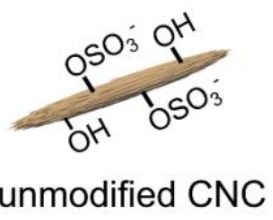

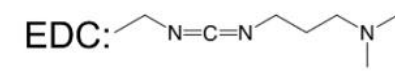
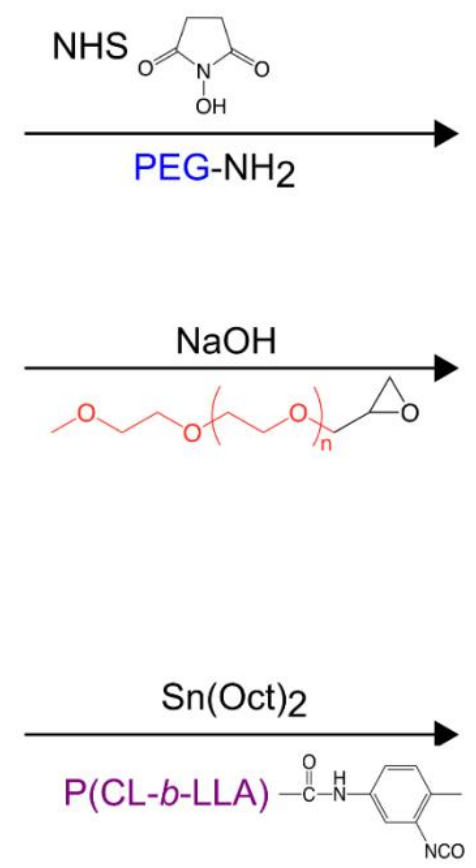
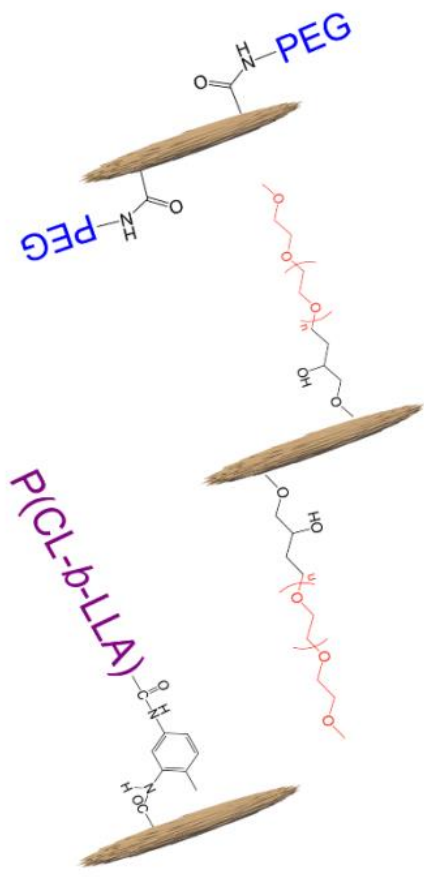

Figure 2. Examples of common grafting to reactions to prepare polymer-grafted CNCs: (a) carbodiimide coupling to attach amine terminated poly(ethylene glycol) (PEG-NH2) to carboxylated CNCs [48], (b) epoxy ring opening in basic conditions to attach epoxy terminated poly(ethylene oxide) to desulfated CNCs [36], and (c) isocyanate mediated grafting to to attach poly(caprolactone-block-L-lactide) (P(CL-b-LLA)) to unmodified CNCs [49].

Carbodiimide coupling between polymers and CNCs (Figure 2a) has been performed using amine terminated polymers and carboxylic acid functional groups on the CNC surface. Therefore, unmodified CNCs produced via sulfuric acid hydrolysis containing sulfate half-ester surface groups require additional functionalization (for example, 2,2,6,6-tetramethylpiperidine-1-oxyl (TEMPO) modification [25]) to impart carboxylic acid surface groups prior to the grafting of polymers. CNCs with carboxylic acid groups can also be produced from $\mathrm{HCl}$ hydrolyzed $\mathrm{CNCs}$ that are TEMPO oxidized either before [44] or after [25] the hydrolysis. This linker chemistry is favourable as it results in one nitrogen atom per polymer linkage and can therefore be easily characterized to determine graft density via elemental analysis as long as the polymer does not contain nitrogen. Carbodiimide coupling chemistry has proven to be highly effective and can be used to graft polymers to $\mathrm{CNCs}$ at relatively high surface coverage. Common solvents used are water (used to graft $400 \mathrm{~g} / \mathrm{mol}$ [50] and $1000 \mathrm{~g} / \mathrm{mol}$ [48] poly(ethylene glycol)) and DMF (used to graft hydrophobic $4840 \mathrm{~g} / \mathrm{mol}$ polystyrene (PS) and $10530 \mathrm{~g} / \mathrm{mol}$ poly(tert-butyl acrylate) [51]). 
These are ideal solvents for polymer grafting to reactions since CNCs are colloidally stable in both water and DMF and more uniform surface functionalization is presumed for systems where CNCs are well dispersed [33].

Polymer grafting to CNCs via epoxy ring opening (Figure $2 b$ ) also requires the polymer to be end functionalized, however with an epoxy ring as opposed to amine terminated for carbodiimide coupling. Epoxy ring opening chemistry relies on the deprotonation of CNC surface hydroxyl groups (therefore no initial CNC modification is required), which occurs at high $\mathrm{pH}$, e.g. $\mathrm{pH}>10$. This chemistry has been effective in grafting polymers in water [36] and dioxane [52]. Characterization of polymer-grafted CNCs using epoxy ring opening can be challenging since the polymer is attached to the $\mathrm{CNC}$ via an ether bond already present in unmodified CNCs, however, characterization methods such as water contact angle [52] and matrix-assisted laser desorption/ionization-time of flight mass spectrometry [36] have been used to confirm successful polymer grafting reactions.

Isocyanate-mediated polymer grafting to $\mathrm{CNCs}$ (Figure 2c) has been used to prepare hydrophobically modified CNCs with polymers such as poly(caprolactone) homopolymer [53] and copolymers [49], poly(urethane) [54], and poly(tetramethylene glycol) [55], typically in a multistep procedure in order to ensure the reaction is strictly between polymer end groups and CNCs. Isocyanate-mediated linker chemistry results in the formation of a carbamate with the CNC hydroxyl groups, but since TDI is most often used, there are at least 2 nitrogen atoms per linker. Alternatively, there can be 3 nitrogen atoms per linker if the other isocyanate groups are reacted with an amine-functionalized polymer to form a urea. However, this linker chemistry has the potential to be easily characterized to determine graft density using elemental analysis to determine nitrogen content, only if the polymer backbone does not contain nitrogen. Since isocyanate moieties are moisture-sensitive, the presence of residual water has a negative impact on reaction yields. In this case, CNCs must either be solvent-exchanged through successive centrifugation steps [53,54] or freeze-dried and re-dispersed [55] in dry organic solvents in order to remove residual water. However, this preparative drawback is counteracted by the high reactivity of isocyanates towards CNC hydroxyl groups, often yielding high surface coverage compared to other grafting to chemistries. 
Table 1. Summary of polymer grafting to CNCs including polymers (in alphabetical order), linker chemistry, reaction solvent, grafted polymer molecular weight (MW), and target application, if reported.

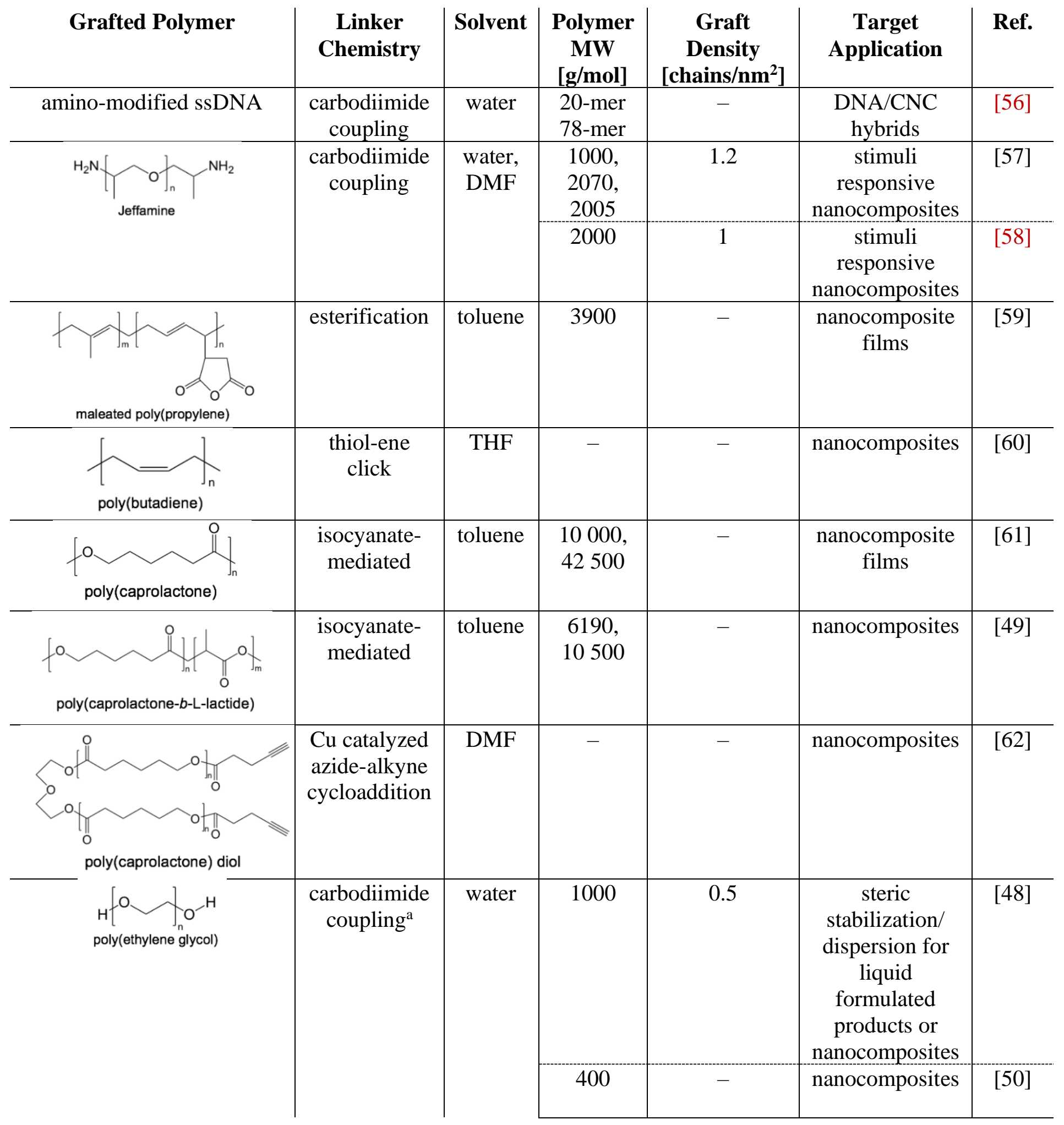




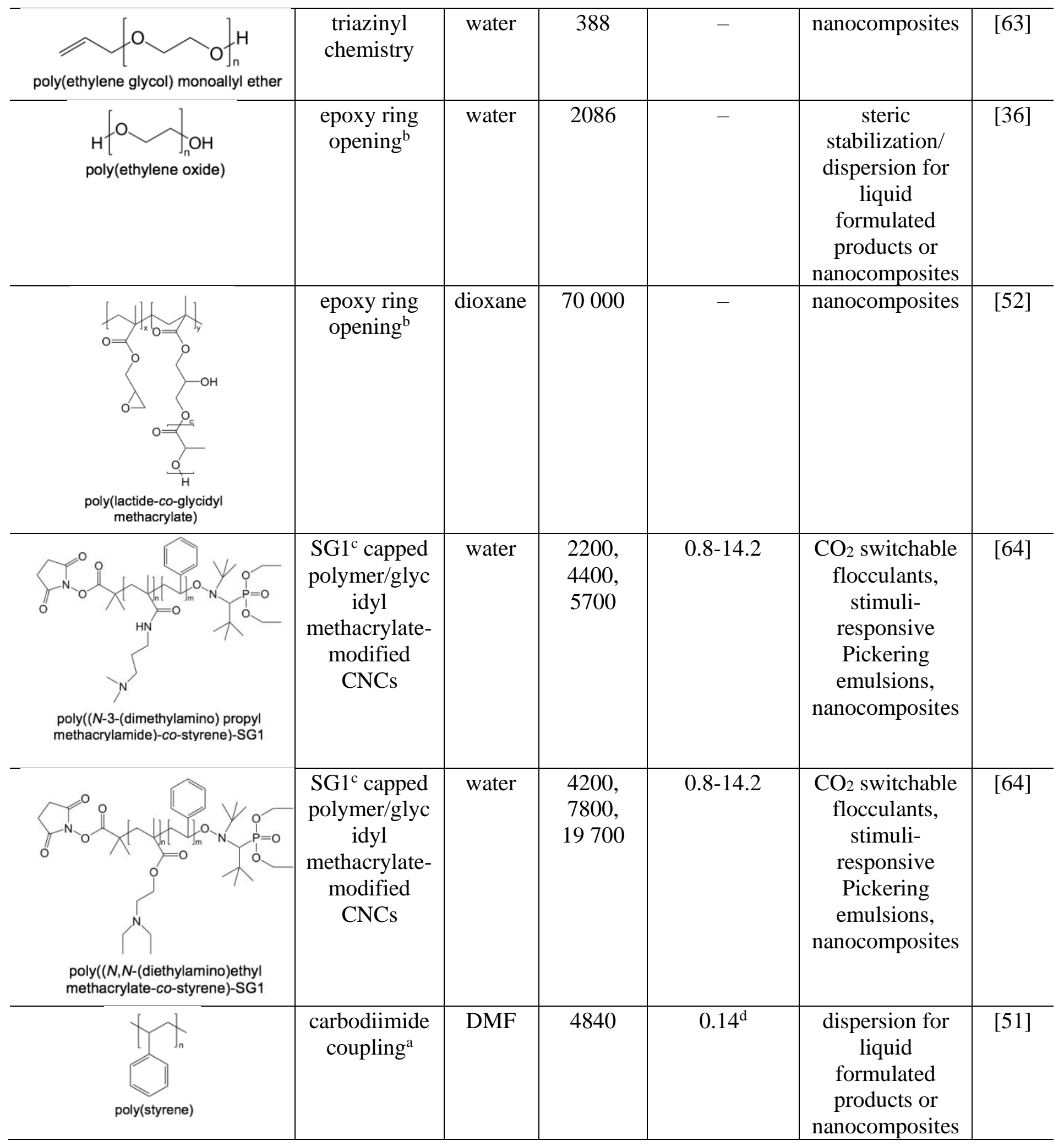




\begin{tabular}{|c|c|c|c|c|c|c|}
\hline poly(tert-butyl acrylate) & $\begin{array}{l}\text { carbodiimide } \\
\text { coupling }^{\mathrm{a}}\end{array}$ & DMF & 10530 & $0.14^{\mathrm{d}}$ & $\begin{array}{l}\text { dispersion for } \\
\text { liquid } \\
\text { formulated } \\
\text { products or } \\
\text { nanocomposites }\end{array}$ & [51] \\
\hline poly(tetramethylene glycol) & $\begin{array}{c}\text { isocyanate- } \\
\text { mediated }\end{array}$ & DMF & 1000 & - & nanocomposites & [55] \\
\hline poly(urethane) & $\begin{array}{c}\text { isocyanate- } \\
\text { mediated }\end{array}$ & DMF & - & - & nanocomposites & [54] \\
\hline
\end{tabular}

${ }^{a}$ Carbodiimide coupling refers to an amine functionalized polymer grafting to carboxylic acid groups on the CNC surface.

${ }^{\text {b}}$ Epoxy ring opening refers to an epoxy terminated polymer reacting with CNC surface hydroxyl groups under alkaline conditions.

'SG1 - N-tert-butyl- $N$-(1-diethylphosphono-2,2-dimethypropyl) nitroxide

${ }^{\mathrm{d} A p p r o x i m a t e}$ grafting density was calculated from the \% polymer reported based on calculations outlined in reference [65] and assuming CNC dimensions of $120 \mathrm{~nm}$ in length and $15 \mathrm{~nm}$ in cross-section.

\section{Polymer grafting from CNCs}

Grafting from CNCs provides a modification route where theoretically high grafting densities (hundreds to thousands of polymer chains per $\mathrm{CNC}$ ) may be achieved, and tends to be more popular in the literature, with reports of both hydrophilic and hydrophobic polymers grafted from CNCs. Polymer grafting from CNCs is a rapidly growing research field, with all examples published in the past 10 years. The existing literature can be divided into three categories of grafting from techniques: free radical polymerization, ring opening polymerization (ROP), and controlled radical polymerization (CRP) which is further broken down into three subcategories: atom transfer radical polymerization (ATRP), reversible addition-fragmentation chain-transfer polymerization (RAFT), and nitroxide mediated polymerization (NMP).

The main advantage of grafting from, specifically with controlled polymerization techniques, is the ability to control grafting density as well as graft length [66]. However, grafting from can be a multi-step process, where in many cases the initiator must be immobilized on the CNCs prior to polymerization [67]. Moreover, most (but not all) of the grafting from polymerization reactions reported to date occur in organic solvents where $\mathrm{CNC}$ colloidal stability is not ideal. The tradeoff is that the dispersion of CNCs in organic solvents (and hydrophobic polymers) should improve as the polymerization proceeds, particularly when grafting hydrophobic polymers. 


\subsection{Free Radical Polymerization}

Free radical polymer grafting from $\mathrm{CNCs}$ is a convenient method for grafting polymers on $\mathrm{CNCs}$ as it is carried out in water and does not require a pre-step to attach surface initiators. Instead, water soluble radical initiators react with the cellulose backbone or surface hydroxyl groups resulting in a free radical site from which the polymer can grow. These reaction conditions are favourable for CNCs and help to ensure that the modification occurs on individual nanoparticles as opposed to aggregates. Free radical polymer grafting from $\mathrm{CNCs}$ has been demonstrated with ceric ammonium nitrate (CAN), potassium persulfate (KPS), and ammonium persulfate (APS) initiators and a range of water soluble monomers (Table 2). Reaction conditions involve elevated temperatures, inert atmospheres to ensure radicals are not terminated early, and thorough mixing. Typical applications for CNCs grafted via aqueous free radical polymerization are for improved compatibility and incorporation into polymer nanocomposites, for in situ incorporation into polymer-CNC hydrogels, or to impart responsive behavior and control colloidal stability and interface stabilizing abilities of CNCs.

Free radical polymer grafting from CNCs with CAN was first demonstrated by Kan et al. who grafted $\mathrm{CNCs}$ with the hydrophilic, $\mathrm{pH}$ responsive polymer poly(4-vinylpyridine) (P4VP). Grafting P4VP from CNCs resulted in $\mathrm{pH}$ responsive CNCs that showed potential as reversible flocculants [68]. Pracella et al. [69] also used CAN to graft poly(glycidyl methacrylate) from $\mathrm{CNCs}$ in order to improve CNC compatibility in nanocomposites. Furthermore, Tang et al. showed that both poly(oligoethylene glycol) methacrylate (POEGMA - a thermally responsive polymer) and poly(methacrylic acid) (PMAA - a pH responsive polymer) could be grafted from CNCs by sequentially using CAN to graft POEGMA and then APS to graft PMAA [70]. CAN has also been used to graft hydrophobic PMMA from CNCs [71]. Similarly, ceric salt was used to graft poly(acrylamide) from CNCs resulting in nanocomposite hydrogels [72]. One slight complication in these water-based polymerizations is that the $\mathrm{CNCs}$ tend to aggregate as the polymer chains grow and entangle (and become less hydrophilic); to surmount this issue, sonication was found suitable to provide sufficient energy and mass transfer during polymerization to reduce the formation of locally aggregated regions $[68,71]$. 
KPS has been used to graft hydrophilic polymers such as poly(acrylamide) [73-75], poly(acrylic acid) [76,77], poly (methacrylic acid-co-ethylene sulfonic acid) [78], the hydrogen bonding moiety 2-ureido-4[1H]-pyrimidone [79], and recently hydrophobic poly(styrene) (PS) [80] from CNCs. The reactions have all been performed in aqueous media and have typically been intended for CNC-polymer hydrogels [73,74,76,77,79] or improving the compatibility between CNCs and hydrophobic polymers [80].

APS has only been used to graft hydrophilic polymers from CNCs. Tang et al. grafted poly[2(dimethylamino)ethyl methacrylate] (PDMAEMA) from CNCs in order to prepare dual responsive Pickering emulsions, as PDMAEMA has both $\mathrm{pH}$ and thermoresponsive behavior [81]. Similarly, APS has been used to graft another thermoresponsive polymer, poly( $N$-isopropylacrylamide) (PNIPAM) to prepare thermoresponsive hydrogels [82].

Other methods of free radical polymer grafting from $\mathrm{CNCs}$ involve the use of a pre-attached bis(acyl)phosphane oxide photoinitiator [83], or using the Graftfast method [84]. The bis(acyl)phosphane oxide-modified CNCs were dispersed in ethanol and grafted with hydrophobic polymers such as poly(methyl methacrylate) (PMMA), poly(butyl acrylate) (PBA), and hydrophilic PNIPAM to achieve $300-477 \%$ polymer by mass [83]. The Graftfast method uses chemical reduction of diazonium salts by reducing agents in the presence of vinyl monomers and has been used to graft PS from CNCs in water [84].

The pitfalls of free radical polymer grafting from $\mathrm{CNCs}$ are the inability to control the grafted polymer length (and polydispersity) and the grafting density, leading to a heterogeneous modification that is typically difficult to characterize. Moreover, free radical polymerization in general is known to lead to high polydispersity due to the lack of control over termination reactions. Most papers on free radical polymer grafting from $\mathrm{CNCs}$ do not report the grafted amount, and if it is reported, it is typically under $20 \%$ by weight (Table 2). Additionally, a significant amount of free homopolymer (not grafted on the CNCs) is produced as a side reaction and can be difficult to separate from the modified CNCs, leading to impure products. For some applications (e.g. if the grafted $\mathrm{CNCs}$ are to be added to a bulk polymer to produce nanocomposites), producing "side" homopolymer may not be detrimental, however, the yield of 
polymer-grafted CNCs is low which may make it less suitable for scale-up despite the advantage of working in water under mild conditions.

Table 2. Summary of free radical polymerization grafting from CNCs including monomers (in alphabetical order), initiator used, amount of polymer grafted from the CNCs (where reported), and the target application discussed in the paper. All reactions were carried out in aqueous environment except reference [83].

\begin{tabular}{|c|c|c|c|c|}
\hline Monomer & Initiator & $\begin{array}{c}\text { Amount of } \\
\text { Polymer Grafted } \\
\text { (wt.\%) }\end{array}$ & Target Application & Ref. \\
\hline $\begin{array}{l}\text { dihydropyrimidin-2-yo-yur } \\
\text { ethyl methacrylate }\end{array}$ & KPS & 7 & cell adhesive hydrogels & {$[79]$} \\
\hline $\begin{array}{r}\text { 2-(dimethylamino) } \\
\text { methacrylate }\end{array}$ & APS & 11 & $\begin{array}{l}\text { responsive Pickering } \\
\text { emulsions }\end{array}$ & [81] \\
\hline 4-vinyl pyridine & CAN & - & $\begin{array}{l}\mathrm{pH} \text { responsive } \\
\text { flocculants }\end{array}$ & {$[68]$} \\
\hline & KPS & - & $\begin{array}{c}\text { nanocomposite } \\
\text { hydrogels }\end{array}$ & {$[73-75]$} \\
\hline acrylamide & ceric salt & 60 & $\begin{array}{c}\text { nanocomposite } \\
\text { hydrogels }\end{array}$ & {$[72]$} \\
\hline acrylic acid & KPS & - & $\begin{array}{l}\text { nanocomposite } \\
\text { hydrogels }\end{array}$ & {$[76,77]$} \\
\hline $\begin{array}{l}\text { butyl acrylate } \\
\text { b }\end{array}$ & $\begin{array}{l}\text { bis(acyl)phosphane } \\
\text { oxide }\end{array}$ & $300-477$ & - & {$[83]$} \\
\hline $\begin{array}{l}\text { di(ethylene glycol) met } \\
\text { ether methacrylate }\end{array}$ & CAN & $11.5^{*}$ & $\begin{array}{l}\text { stimuli responsive } \\
\text { colloids }\end{array}$ & {$[70]$} \\
\hline
\end{tabular}




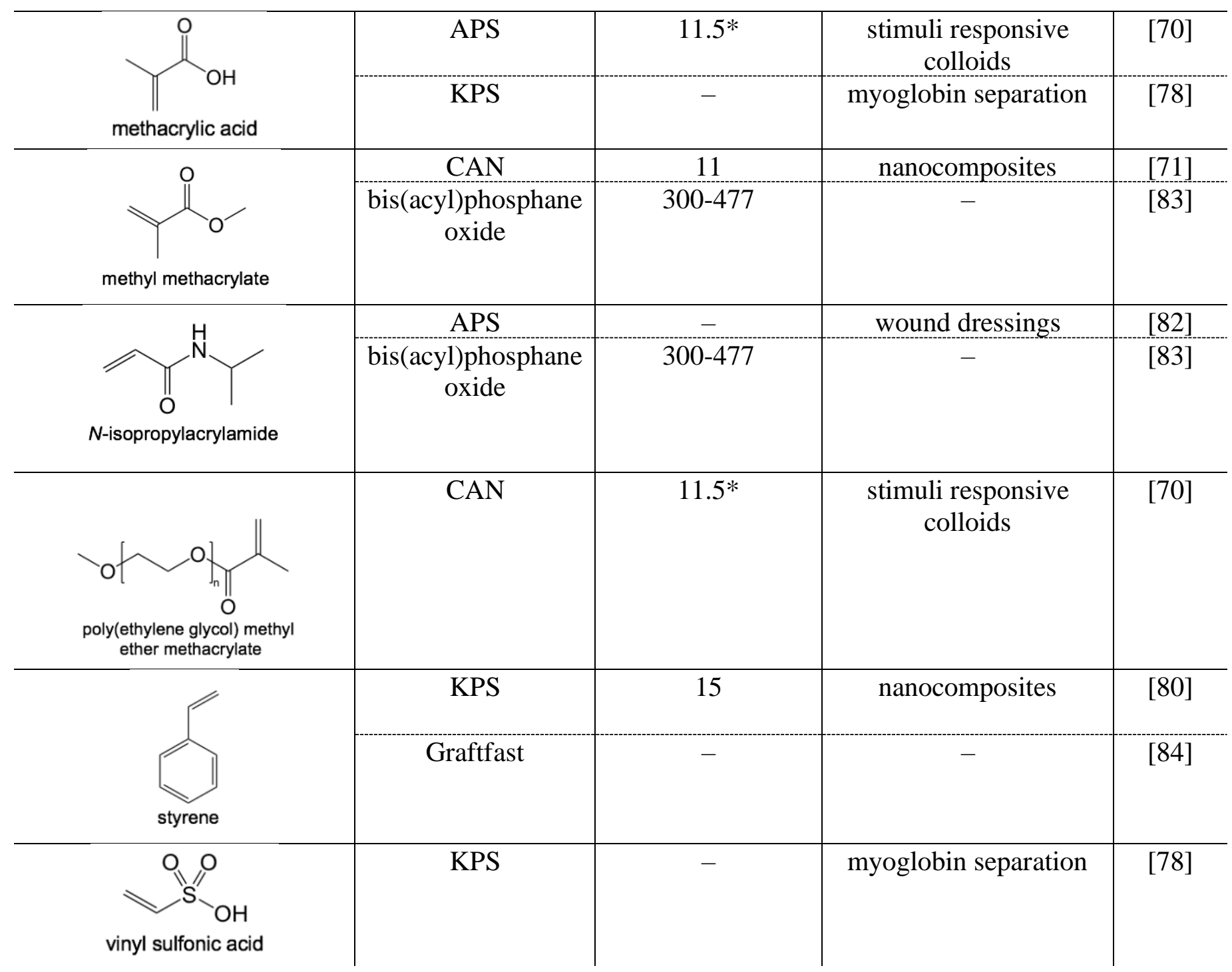

*Represents total amount of polymer, as two different polymers were grafted.

\subsection{Ring Opening Polymerization}

Given the abundance of hydroxyl groups present at the CNC surface, ROP is a common approach to graft polymers from CNCs [85-87]. ROP of cyclic monomers, such as $\varepsilon$-caprolactone ( $\varepsilon$-CL) [86,87,96-98,88-95], $l$-lactide ( $l$-LA) [90,98,107,108,99-106], and $d$-lactide ( $d$-LA) [94,109-111] can be initiated directly from these- $\mathrm{OH}$ groups. The first synthetic pathways for grafting polymers from CNCs were, in fact, developed based on surface-initiated ROP from -OH groups [86]. The main interest in grafting such polyesters from CNCs is toward the development of biobased and biodegradable nanocomposites, which have great potential for biomedical devices and packaging [85]. Shown in Table 3 is a summary of published work on ROP from CNCs, including solvent, degree of polymerization (DP), contact angle, and reported target application (where provided). In 
all reported work, the grafting density is not reported, likely owing to the fact that there is no bond formation between the CNCs and polymer that can be distinguished from unmodified CNCs. The majority of the initial work in this area focused on ROP of $\varepsilon$-CL, which is conducted in organic solvents, such as toluene $[86,89-95,98]$, or in bulk $[87,88,96,97]$ due to the low moisture tolerance of the reaction. To work in toluene, $\mathrm{CNCs}$ are solvent exchanged from water to acetone to toluene via successive centrifugation, or dry CNCs are dispersed in toluene via sonication, however, even if separated initially, aggregation and sedimentation of CNCs in toluene is very fast (but can be partially mediated through constant stirring), and likely leads to non-uniform surface modifications. Polylactic acid (PLA) was also grafted from CNCs in DMSO [107]. In general, polyesters, such as poly- $\varepsilon$-caprolactone (PCL) and PLA, have most often been grafted from CNCs using tin(II) 2-ethylhexanoate $\left(\mathrm{Sn}(\mathrm{Oct})_{2}\right)$ as a catalyst, with temperature ranges of 80 to $130{ }^{\circ} \mathrm{C}$ [86,88,100-104,106,107,109,110,89,91-96,99]. Under such conditions, ROP proceeds via a coordination-insertion mechanism [85]. Other inorganic compounds, such as magnesium hydride $\left(\mathrm{MgH}_{2}\right)$ [105] and zinc oxide [107], and organic compounds, such as citric acid [97], tartaric acid [91], and 4-dimethylaminopyridine (DMAP) [91,112] have also been used to catalyze ROP from CNCs. Chang et al. reported bulk ROP of $\varepsilon$-CL catalyzed by $\mathrm{Sn}(\mathrm{Oct})_{2}$ under microwave irradiation, which resulted in high PCL contents [88,96]. In one of these studies, the authors obtained PCL contents of 90-96\%, yielding thermoformable one-component nanocomposites [96]. Given the relative hydrophobicity of such polyesters, the water contact angle of the resulting CNCs grafted with PCL typically falls within the range of $70-90^{\circ}$ (Table 3 ).

The primary disadvantage of ROP of lactones and lactides from CNCs is the moisture sensitivity, which necessitates either drying and re-dispersing CNCs in organic solvents using high energy sonication or laborious solvent-exchange assisted by centrifugation. Moreover, the existence of ester functional groups along the polymer chains does not allow a straightforward means to cleave polymers off of CNCs and analyze them by standard techniques, such as gel permeation chromatography (GPC). Therefore, little is known regarding the molecular weight and polydispersity of the grafted polyesters themselves. The use of sacrificial initiators, such as benzyl alcohol [107], provides a method to estimate the physical properties of the grafted polyesters, although one must assume that the kinetics of the simultaneous solution ROP are analogous to those initiated from the CNC surface. This approach has also been utilized during the grafting of 
PCL from other types of cellulosic nanoparticles [113]. This investigation determined the surface coverage of CNCs to be between 3-7\% of anhydroglucose units (AGUs) with PCL molecular weights from 4-11 kDa (DP of 15-43) and polydispersities of 1.2-1.4. Luiz de Paula et al. used ${ }^{1} \mathrm{H}$ and ${ }^{13} \mathrm{C}$ NMR spectroscopy of PLA- $g$-CNCs to determine a DP of 12 for the grafted polymers [105]. Wu et al. estimated a DP of 24 for similar systems based on FTIR spectroscopy [111].

Most often, hydrophobic polyesters are grafted from CNCs via ROP, however a few hydrophilic polymer brushes have also been successfully synthesized, namely oxazolines [114,115]. Since the mechanism of oxazoline ROP is cationic, tosylation of hydroxyl groups is first necessary [115]. Here, tosylated CNCs were used for bulk ROP of 2-ethyl-2-oxazoline. 2-Methyl-2-oxazoline and 2-n-propyl-2-oxazoline were further grafted from poly(2-isopropenyl-2-oxazoline)-modified CNCs to give bottle brush-type polymer grafts [114]. Indocyanine green (ICG) was then immobilized on these bottle brush-modified $\mathrm{CNCs}$ via electrostatic interactions toward photothermal cancer therapeutic agents. 
Table 3. Summary of ring opening polymerization grafting from CNCs including monomers (in alphabetical order), polymerization solvent, degree of polymerization (DP), contact angle, and target application, where reported.

\begin{tabular}{|c|c|c|c|c|c|}
\hline Monomer & $\begin{array}{c}\text { Polymerization } \\
\text { Solvent }\end{array}$ & DP & $\begin{array}{c}\text { Contact } \\
\text { Angle }\end{array}$ & $\begin{array}{c}\text { Target } \\
\text { Application }\end{array}$ & Ref. \\
\hline \multirow{11}{*}{$\varepsilon$-caprolactone } & \multirow{5}{*}{ toluene } & \multirow{5}{*}{-} & $\sim 78$ & nanocomposites & {$[86]$} \\
\hline & & & - & nanocomposites & {$[89,90,93-95]$} \\
\hline & & & 70 & - & [91] \\
\hline & & & 82 & - & [92] \\
\hline & & & - & - & [108] \\
\hline & \multirow{4}{*}{ bulk monomer } & \multirow{4}{*}{-} & - & - & [87] \\
\hline & & & 89 & $\begin{array}{l}\text { one-component } \\
\text { nanocomposites }\end{array}$ & [96] \\
\hline & & & $\sim 78$ & - & [97] \\
\hline & & & - & nanocomposites & {$[88]$} \\
\hline & \multirow{2}{*}{$\begin{array}{l}\text { bulk monomer } \\
\text { (microwave) }\end{array}$} & \multirow[t]{2}{*}{-} & 89 & $\begin{array}{l}\text { one-component } \\
\text { nanocomposites }\end{array}$ & [96] \\
\hline & & & - & nanocomposites & {$[88]$} \\
\hline 2-ethyl-2-oxazoline & $\begin{array}{l}\text { bulk monomer } \\
\text { (microwave) }\end{array}$ & - & - & $\begin{array}{c}\text { post- } \\
\text { polymerization } \\
\text { modification }\end{array}$ & {$[115]$} \\
\hline $\begin{array}{r}\square \\
2-m \epsilon \\
\text { oxa }\end{array}$ & acetonitrile & - & - & $\begin{array}{l}\text { photothermal } \\
\text { cancer therapy } \\
\text { (bottle brushes) }\end{array}$ & [114] \\
\hline oxazoline & acetonitrile & - & - & $\begin{array}{l}\text { photothermal } \\
\text { cancer therapy } \\
\text { (bottle brushes) }\end{array}$ & {$[114]$} \\
\hline & & - & - & $\begin{array}{c}\text { shape-memory } \\
\text { polymers }\end{array}$ & [98] \\
\hline & toluene & - & - & nanocomposites & $\begin{array}{c}{[90,94,110,99-} \\
101,103,104,106,108,109]\end{array}$ \\
\hline & & - & - & - & {$[102]$} \\
\hline $\begin{array}{c}0 \\
0\end{array}$ & & 24 & - & nanocomposites & {$[111]$} \\
\hline & DMSO & - & 76 & nanocomposites & [107] \\
\hline & bulk monomer & 12 & - & nanocomposites & {$[105]$} \\
\hline
\end{tabular}




\subsection{Controlled Radical Polymerization}

Controlled radical polymerization (CRP), also known as reversible-deactivation radical polymerization (RDRP), has given rise to an unlimited number of new polymeric materials with improved macroscopic properties resulting from a comprehensive understanding of structureproperty relationships as well as guidelines based on theoretical predictions [116]. CRP is characterized by a combination of fast initiation and minimal termination, along with a dynamic equilibrium between propagating radicals and a given dormant species. Fast exchange among active and dormant species is required for good control over molecular weight, polydispersity, and chain architecture in all CRP systems. A growing species should ideally react only with a few monomer units before it is deactivated to the dormant state. In particular, surface initiated CRP provides a sophisticated method of tailoring the chemical and physical properties of interfaces and can be used to design better nanocomposites with improved properties owing to the enhanced interfacial interactions between matrix and filler [117]. To date, three types of CRP have been used to graft from $\mathrm{CNCs}$ including atom transfer radical polymerization (ATRP), reversible additionfragmentation chain-transfer polymerization (RAFT), and nitroxide mediated polymerization (NMP) [118]. Each type of CRP allows for control over the polymer graft length, and the addition of initiating groups to the $\mathrm{CNC}$ surface prior to polymerization allows for control over the polymer grafting density.

Grafting density and graft length play an important role in the addition of polymer-grafted CNCs into hydrophobic polymers and organic solvents and are important properties that can be tuned for a desired application [118]. For example, improving compatibility between polymer-grafted $\mathrm{CNCs}$ and organic solvents may require steric stabilization where the critical grafting density would be below the point of entanglement between neighboring chains [65]. However, for some applications, such as incorporation into polymer latexes or polymer nanocomposites, the CNCs may only require a dense, short chain modification. It is therefore important to consider optimizing grafting density and graft length for a particular application such that the desired properties are achieved without exceeding steric stabilization or "overcompensating" with excess polymer that may not be necessary. 


\subsubsection{Atom Transfer Radical Polymerization}

Transition metal-mediated controlled radical polymerization provides a method for grafting polymers from $\mathrm{CNCs}$ with excellent control over both graft length and grafting density. Of the various transition metals that have been used to catalyze $\mathrm{CRP}, \mathrm{Cu}$ species are the most widely employed. Several variants of $\mathrm{Cu}$-mediated CRP have been reported, which differ in the electron transfer mechanism [119]. Some examples include single-electron transfer living radical polymerization (SET LRP) [120] and activators (re)generated by electron transfer (A(R)GET) ATRP [121]. In the case of polymer grafting from CNCs, normal atom transfer radical polymerization (ATRP) is commonplace. The first report of using ATRP from a cellulose substrate (filter paper) was by Malmström and Carlmark [122], and since then, many examples of using surface initiated ATRP (SI-ATRP) from CNCs have been demonstrated (Table 4). In order to perform SI-ATRP from CNCs, an initiator grafting step is necessary in order to convert the CNC surface into a macroinitiator. This is typically done in organic solvents such as tetrahydrofuran (THF) or DMF, using triethylamine (TEA) and 4-(dimethylamino)pyridine (DMAP) to attach $\alpha$ bromoisobutyryl bromide (BiBB) to the available hydroxyl groups on the $\mathrm{CNC}$ surface, with an example shown in Figure 3. While DMF has been shown to be an acceptable solvent for dispersing CNCs, preparing a proper dispersion of CNCs in THF (i.e., where the CNCs are not aggregated) is difficult. Most literature examples use sonication to disperse freeze dried CNCs in organic solvents, where it is assumed that sonication energy can break up the CNC aggregates into individual CNCs. The vast majority of reported examples of SI-ATRP from CNCs use the initiator attachment protocol involving TEA, DMAP, and BiBB, however bromoisobutyric acid with 1,1'carbonyldiimidazole in dichloromethane has also been shown to be effective [123,124]. Furthermore, recent work has used a water-based approach (albeit still a multi-step process) to attach 2-bromoisobutanoic acid $N$-hydroxysuccinimide ester to $\mathrm{CNCs}$ that were oxidized and modified with ethylenediamine [125]. This is a significant step towards maintaining the "green" aspect of $\mathrm{CNCs}$, whereby the initiator attachment and polymer grafting were performed in water. In another advancement, Boujemaoui et al. [126] used a functional acid (2-bromopropionic acid) during the hydrolysis of cellulose in order to prepare functionalized CNCs with SI-ATRP initiating groups, all in one step during $\mathrm{CNC}$ production. This is significant if controlled polymer grafting from $\mathrm{CNCs}$ is anticipated to be used at an industrial scale. 


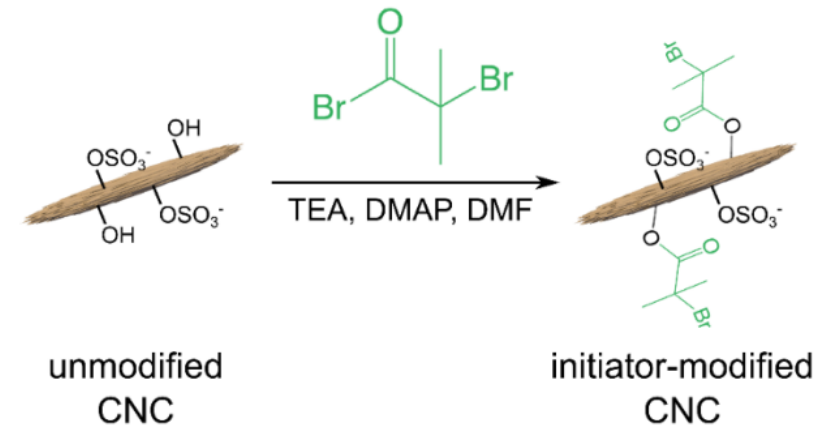

Figure 3. Schematic of the most common method for attaching ATRP surface initiators to CNCs, adapted from reference [127].

While there have been many reported methods of attaching ATRP initiator groups to the CNC surface, little is reported on the efficiency and reproducibility of these reactions. Zoppe et al. [128] studied the effect of CNC surface charge (i.e., sulfate half ester groups) on the initiator efficiency while grafting in aqueous media and found that $\mathrm{CNCs}$ with higher charge density had higher initiator efficiency at the expense of high polydispersity caused by inefficient deactivation. Morandi et al. showed that an increasing amount of $\mathrm{Br}$ content can be correlated to an increase in the volume of initiator introduced in the attachment step, but there was no report of reproducibility or efficiency of the reaction [67]. This remains a critical step in the SI-ATRP grafting from CNCs, as grafting density is directly related to the initiator attachment efficiency. Elemental analysis is the most common method to quantify the amount of initiating groups on the CNC surface (where $\mathrm{Br}$ can be detected and correlated to the number of initiating sites per $\mathrm{CNC}$ ). Therefore, until a systematic study is performed and can predict the efficiency and reproducibility of the initiator attachment step, quantification through elemental analysis is critical. Furthermore, purification of the CNC starting material with methods such as Soxhlet extraction have been shown to result in more reproducible and efficient surface modifications [129] and may result in more consistent reports of polymer grafting density. This is critical, as some reports have indicated that adsorbed oligosaccharides are present on the surface of purified CNCs depending on the hydrolysis reaction conditions [130], which can hinder functionalization of CNC surface hydroxyl groups and grafting yields. 
The first report of SI-ATRP grafting from CNCs was by Yi et al. [131] who grafted PS. A comprehensive list of polymers grafted from CNCs via SI-ATRP is shown in Table 4. Morandi et al. [67] also grafted PS from CNCs (Figure 4a) and showed a series of PS-g-CNCs with varying grafting densities. In their work, the grafted polymer was cleaved from the surface and characterized to show that good control over the SI-ATRP was achieved [47]. If a non-cleavable ATRP initiator is used, as in most cases, a sacrificial initiator (that is a free initiator in solution with similar properties to the initiating groups on the $\mathrm{CNC}$ surface) is added to the reaction in order to polymerize free polymer which is collected and characterized to measure the MW and polydispersity (PDI) of the grafted polymer. Most common for systems with BiBB as the surface initiator, ethyl $\alpha$-bromoisobutyrate $(\mathrm{EBiB})$ is used as sacrificial initiator. Although discrepancies between free polymer and polymer grafted from the CNCs are likely, until recently this has been reported to be the most accurate method of determining the MW and PDI of polymer grafted from the CNC surface, and Morandi et al. [47] showed that the MW and PDI of grafted polymer cleaved from the CNC surface was similar to that of homopolymer polymerized from sacrificial initiator. In a recent report by Zhang et al. [132], elemental analysis of initiator-modified CNCs was combined with thermal gravimetric analysis (TGA) and dynamic light scattering (DLS) of the polymer-grafted CNCs to calculate the weight average MW of the polymer grafted from CNCs, without the need to cleave the polymer chains from the CNC surface. The authors prepared PS- $g$ CNCs and compared the mass of grafted PS (deduced from the TGA curves) with the amount of initiating sites (determined by elemental analysis) and matched theoretical values calculated according to monomer conversion with the MW of the polymer prepared via sacrificial initiator. The MW matched that of the free polymer, and the combination of characterization methods has been proposed as a convenient method for characterizing polymer graft length. 


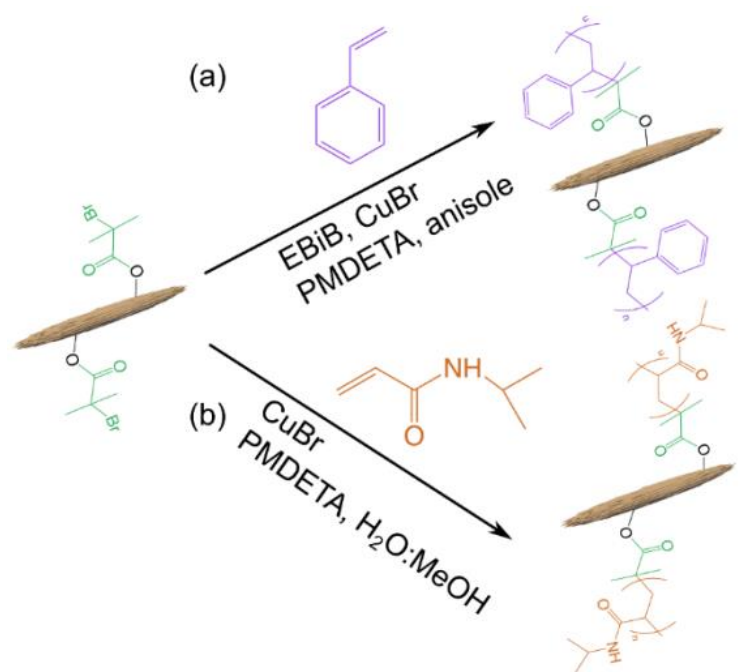

Figure 4. Examples of SI-ATRP grafting of (a) styrene [67] and (b) $N$-isopropylacrylamide [133] from initiator-modified CNCs.

Table 4. Summary of the literature on SI-ATRP grafting from CNCs, including monomers (in alphabetical order divided by hydrophobic and hydrophilic polymers), polymerization solvent, target degree of polymerization (DP), grafting density (calculated approximately here from $\mathrm{Br}$ content of initiator-modified CNCs, where reported), contact angle, and target application, where reported. All examples used CNCs grafted with $\mathrm{BiBB}$ in a pre-polymerization step except references [123,124] which grafted bromoisobutyric acid or 2-bromoisobutanoic acid [125], reference [47] which used a photo-cleavable initiator, and reference [126] where the initiatormodified CNCs were prepared during hydrolysis.

\begin{tabular}{|c|c|c|c|c|c|c|}
\hline Monomer & $\begin{array}{c}\text { Polymerization } \\
\text { Solvent }\end{array}$ & $\begin{array}{c}\text { Target } \\
\text { DP }\end{array}$ & $\begin{array}{c}\text { Grafting } \\
\text { Density }^{\mathrm{x}} \\
{\text { (chains } / \mathbf{n m}^{2} \text { ) }}\end{array}$ & $\begin{array}{c}\text { Contact } \\
\text { Angle }\end{array}$ & $\begin{array}{c}\text { Target } \\
\text { Application }\end{array}$ & Ref. \\
\hline \multicolumn{7}{|c|}{ Hydrophobic polymers } \\
\hline & chlorobenzene & 100 & - & - & - & {$[134]$} \\
\hline \multicolumn{7}{|c|}{ 6-[4-(4-methoxyphenylazo)phenoxy]hexyl methacrylate } \\
\hline \multirow[t]{2}{*}{$\begin{array}{l}\text { O butyl acrylate } \\
\text { lat }\end{array}$} & bulk monomer & 1000 & $1-20$ & - & $\begin{array}{l}\text { thermoplastic } \\
\text { elastomer } \\
\text { reinforcement }\end{array}$ & [135] \\
\hline & toluene & $\begin{array}{l}50 \\
200\end{array}$ & 1 & $50-130^{\circ}$ & $\begin{array}{c}\text { nanocomposite } \\
\text { latex } \\
\text { particles[65] }\end{array}$ & {$[65]$} \\
\hline
\end{tabular}




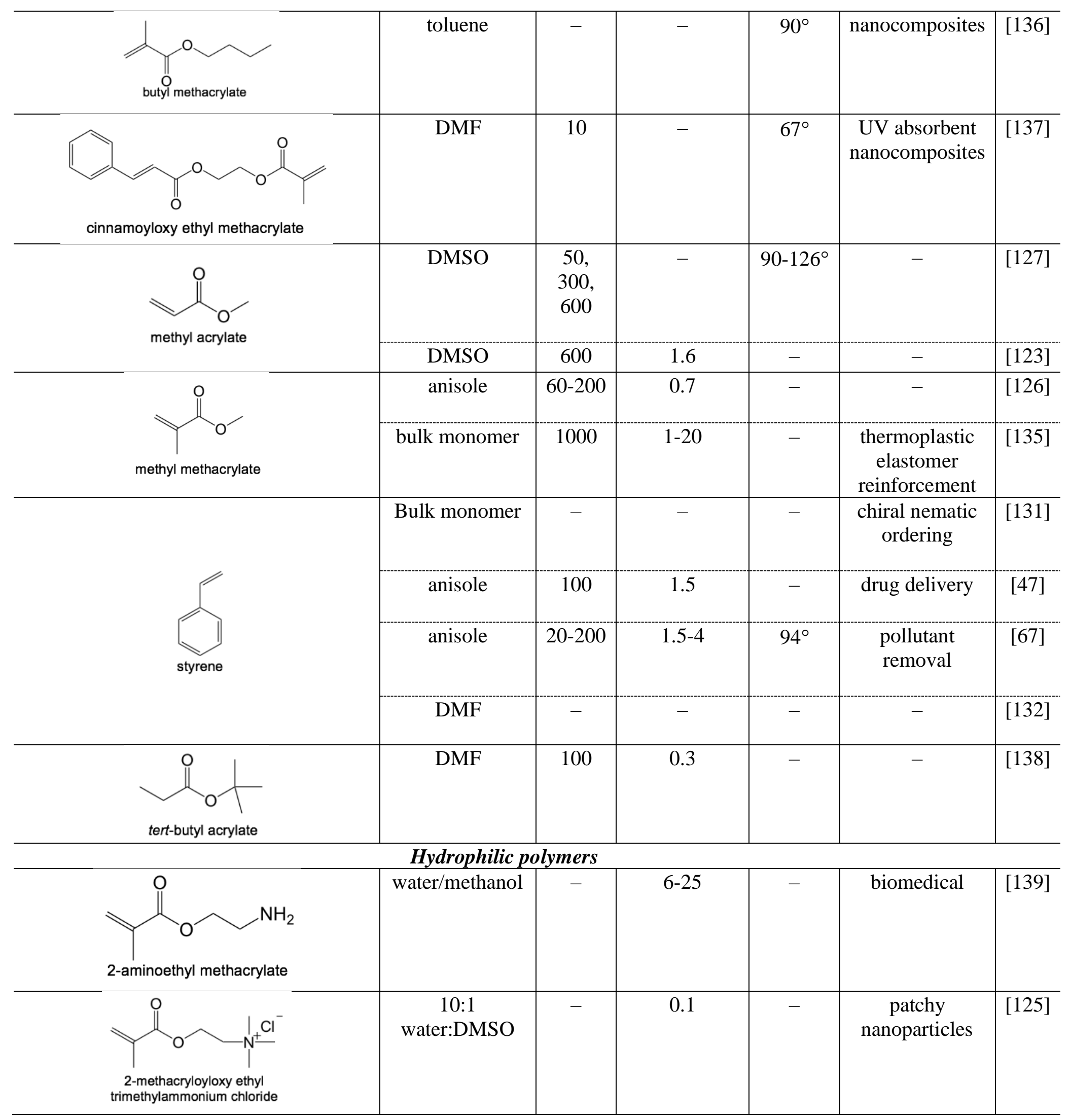




\begin{tabular}{|c|c|c|c|c|c|c|}
\hline 4-ethoxy-9-allyl-1,8-naphthalimide & water/methanol & 200 & 4 & $30-60^{\circ}$ & - & [140] \\
\hline \multicolumn{7}{|l|}{ 4-vinyl pyridine } \\
\hline \multirow[b]{2}{*}{ diethylaminoethyl methacrylate } & methanol & 500 & 0.05 & - & $\begin{array}{c}\mathrm{CO}_{2} \text { responsive } \\
\text { colloids }\end{array}$ & {$[124]$} \\
\hline & $\mathrm{DMF}$ & $\begin{array}{c}10,25, \\
50\end{array}$ & 2 & - & $\begin{array}{l}\text { Si nanorod } \\
\text { template }\end{array}$ & [142] \\
\hline \multicolumn{7}{|l|}{ di(ethylene glycol) methyl ether methacrylate } \\
\hline \multirow{3}{*}{ dimethylaminoethyl methacrylate } & methanol & 500 & 0.05 & - & $\begin{array}{c}\mathrm{CO}_{2} \text { responsive } \\
\text { colloids }\end{array}$ & [124] \\
\hline & methanol & 60 & - & - & $\begin{array}{l}\text { chiral nematic } \\
\text { films }\end{array}$ & [144] \\
\hline & $\mathrm{DMF}$ & 500 & 1 & - & $\begin{array}{l}\text { high affinity } \\
\text { virus binding }\end{array}$ & {$[145]$} \\
\hline$\left.\right|_{n \text {-(2-aminoethylmethacrylamide) }}$ & water/methanol & - & $6-25$ & - & biomedical & [139] \\
\hline \multirow{3}{*}{$\left.\right|_{\mathrm{O} \text {-isopropylacrylamide }} ^{\mathrm{N}}$} & water/methanol & 200 & 4 & $30-60^{\circ}$ & - & [140] \\
\hline & water/methanol & - & $6-25$ & $\begin{array}{l}120^{\circ} \\
\text { (above } \\
\text { LCST) }\end{array}$ & - & [133] \\
\hline & water/methanol & $\begin{array}{l}343 \\
361 \\
\end{array}$ & 0.07 & - & - & [146] \\
\hline
\end{tabular}




\begin{tabular}{|c|c|c|c|c|c|c|}
\hline$\left.\right|_{N, N \text {-dimethylacrylamide }} ^{O}$ & water & - & $0.02,1$ & - & - & [128] \\
\hline N-vinylcaprolactam & water/DMF & - & 2 & - & - & [147] \\
\hline 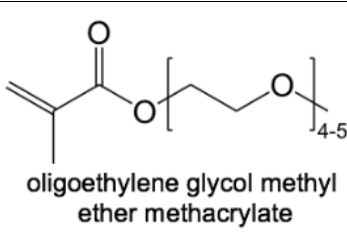 & water/DMF & 25 & - & - & tunable LCST & [143] \\
\hline $\begin{array}{c}\begin{array}{c}\text { poly(ethylene glycol } \\
\text { methacrylate) }\end{array} \\
\text { maH }\end{array}$ & DMF & - & - & - & $\begin{array}{c}\text { films and } \\
\text { biosensors }\end{array}$ & [148] \\
\hline $\begin{array}{c}\text { sodium } \\
\text { 4-vinylbenzenesulfonate }\end{array}$ & $\begin{array}{c}10: 1 \\
\text { water:DMSO }\end{array}$ & - & 0.1 & - & $\begin{array}{c}\text { patchy } \\
\text { nanoparticles }\end{array}$ & [125] \\
\hline
\end{tabular}

${ }^{\mathrm{x}}$ Approximate grafting density was calculated from the $\mathrm{Br}$ content (where reported) based on calculations outlined in reference [65] and assuming CNC dimensions of $120 \mathrm{~nm}$ in length and $15 \mathrm{~nm}$ in cross-section and that all $\mathrm{Br}$ sites were converted to polymer chains.

Since the initial reports of SI-ATRP grafting from CNCs, various functional polymers have been grafted including hydrophobic polymer such as PS [67,131,149], poly(methacrylate) (PMA) [123,127], PMMA [126], poly(6-(4-(4-methoxyphenylazo)phenoxy) hexyl methacrylate) [134], and copolymers of poly(MMA-co-BA) [135] and poly(butyl methacrylate) [136], among other (shown in Table 4). In most cases, hydrophobic polymers are grafted from CNCs to improve CNC compatibility with hydrophobic matrices. However, few reports go on to test the polymer-grafted $\mathrm{CNC}$ dispersion in composites. A notable example of hydrophobic polymer-grafted CNCs used in new applications is recent work by Kedzior et al. [65] who grafted PBA from CNCs at varying graft lengths. They found that above a critical graft length, the polymer-grafted CNCs were too aggregated to be incorporated inside polymer latex particles. This is an important factor to consider 
when altering the surface chemistry of CNCs with polymers - more polymer is not always better, especially when scale-up and industrial production of polymer-grafted CNCs are of interest.

Notably, there are more reported examples of hydrophilic polymers grafted from CNCs via SIATRP. Polymers such as poly(diethylaminoethyl methacrylate) [124], poly(ethylene glycol methylacrylate) [148], poly(oligoethylene glycol) methyl ether acrylate [143], poly([(2methacryloyloxy) ethyl] trimethylammonium chloride) [125], poly(sodium 4vinylbenzenesulfonate) [125], poly(dimethylaminoethyl methacrylate) [124,144,145], PNIPAM [125,133,146] (shown in Figure 4b), PNIPAM fluorescent copolymers [140], poly(N,Ndimethylacrylamide) [128], poly(2-aminoethylmethacrylate) and poly(2aminoethylmethacrylamide) [139], poly(acrylic acid) through hydrolysis of poly(tert-butyl acrylate) [138], and poly(N-vinylcaprolactam) [147] have been grafted from CNCs, typically in polymerization solvents such as water, methanol, DMF, and DMSO, all of which are considered good solvents for proper CNC dispersion.

Since the initiator attachment occurs on available hydroxyl groups on the CNC surface, polymer grafting is expected to occur relatively uniformly across the CNC surface. However, work by Zoppe et al. [125] showed for the first time that site specific surface modification of CNCs with initiating groups could lead to polymer growth preferentially on the ends of CNCs, yielding patchy nanocrystals. NIPAM, [2-(methacryloyloxy)ethyl]trimethylammonium chloride, and sodium 4vinylbenzenesulfonate were polymerized from the CNC ends, and the work proposed the use of CNCs with end-tethered polymer chains as an experimental platform to study the self-assembly of end-functionalized anisotropic nanohybrids.

In all SI-ATRP cases, purification of the products after polymer grafting is necessary to remove the $\mathrm{Cu}$ catalyst. Adsorbed $\mathrm{Cu}$ catalyst results in polymer-grafted $\mathrm{CNCs}$ with a blue or green appearance, depending on the $\mathrm{Cu}$ valency. Typical purification methods involve extensive centrifugation and washing steps and/or separation via $\mathrm{Cu}$ binding to ethylenediaminetetraacetic acid. One way to overcome the cumbersome purification needed to remove catalyst was shown by Wang et al. [123] who used $\mathrm{Cu}(0)$ (copper wire) as the catalyst. This allowed for a simple purification with only a few centrifugation steps. Another example of a SI-ATRP technique that uses significantly less initiator than traditional SI-ATRP used photo-induced ATRP with 50 times 
less $\mathrm{Cu}$, resulting in significantly fewer centrifugation steps to remove the remaining $\mathrm{Cu}$ catalyst [127].

\subsubsection{Reversible Addition-Fragmentation Chain-Transfer Polymerization}

In comparison to ATRP, there are very few reports of using RAFT to polymerize from CNCs. In general, RAFT is known as one of the most successful CRP methods as it is applicable to a wide range of monomers and provides good control owing to the fast exchange reactions between RAFT agent and monomer. RAFT polymerization requires the appropriate selection of a RAFT agent, which is chosen based on monomer. Common RAFT agents are dithioesters, dithiocarbamates, trithiocarbonates, and xanthates [116]. Possibly owing to the more complex nature of RAFT or chain transfer agent attachment, there have been only eight reports of RAFT grafting from CNCs since 2014, all of which are reported in Table 5. The first report, by Zeinali et al. [150] attached 2(dodecylthiocarbonothioylthio)-2-methylpropionic acid (DDMAT) in one step to the CNC surface and polymerized a random copolymer of poly(NIPAM-co-acrylic acid). The goal of this work was to control the lower critical solution temperature for the polymer by tethering from the surface of CNCs. The same authors have also prepared block copolymers of poly(NIPAM-co-acrylic acid) using the same technique [151].

Other examples of using RAFT to graft polymers from CNCs include the work of Anzlovar et al. [152] who attached 4-cyano-4-(phenylcarbonothioylthio)pentanoic acid (CPADB) to CNCs via esterification and grafted PMMA from the surface in order to better incorporate CNCs into a CNC/poly(vinyl acetate) composite. Additionally, work by Boujemaoui et al. [153] used either a one or two step process to attach chain transfer agent (CTA) to the CNC surface, and showed that the one step protocol yielded CNCs with more CTA than the two step procedure. Vinyl acetate was then polymerized from the CTA-CNCs (schematic shown in Figure 5) in order to prepare polymer-grafted CNCs that were used to prepare nanocomposites with improved mechanical properties compared to unmodified CNC nanocomposites [153]. 


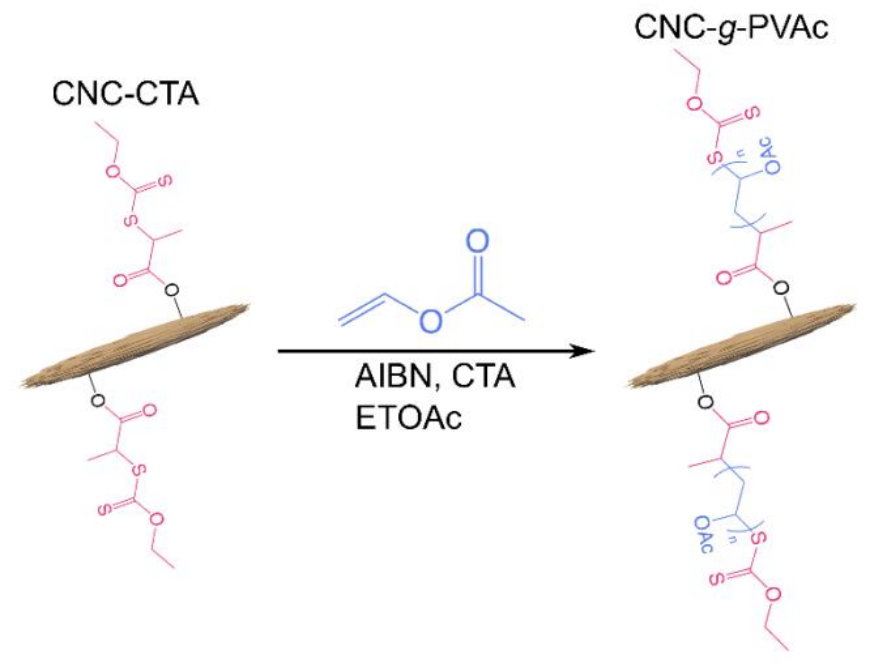

Figure 5. An example of using RAFT to graft vinyl acetate from chain transfer agent-modified CNCs (CNC-CTA) using 2,2'-azobis(2-methylpropionitrile) (AIBN) initiator, free chain transfer agent, in ethyl acetate (ATOAc), adapted from reference [153].

Hu et al. [154] used a multi-step process to perform both RAFT and ATRP from the surface of CNCs. The authors grafted poly(poly(ethylene glycol)ethyl ether methacrylate) via RAFT (Table 5) and poly(2-(dimethylamino)ethyl methacrylate) via ATRP (Table 4). Unmodified CNCs were first functionalized with ATRP initiating sites, followed by functionalization with primary amino groups which were then functionalized with RAFT initiation sites by attaching 4,4'-azobis(4cyanovaleric acid) was to the amino groups. RAFT and ATRP were then carried out sequentially. The target application for this work was the use of polymer-grafted CNCs to conjugate $\mathrm{Au}$ nanoparticles for biomedical applications, and to date this is the only report of using multiple CRP techniques to graft CNCs with two different polymers.

Other work used a free macroRAFT agent in an attempt to control the propagation of free radicals generated at the CNC surface. Liu et al grafted water soluble polymers (poly(acrylamide) $[155,156]$ and poly $(N, N$-dimethylacrylamide) [157]) from CNCs using this method. However, the degree of control was affected by the macroRAFT agent adsorption, concentration, and suspension viscosity. 
Table 5. Summary of the literature involving RAFT polymerization grafting from CNCs including monomers (in alphabetical order), polymerization solvent, target degree of polymerization (DP), grafting density, and target application, where reported.

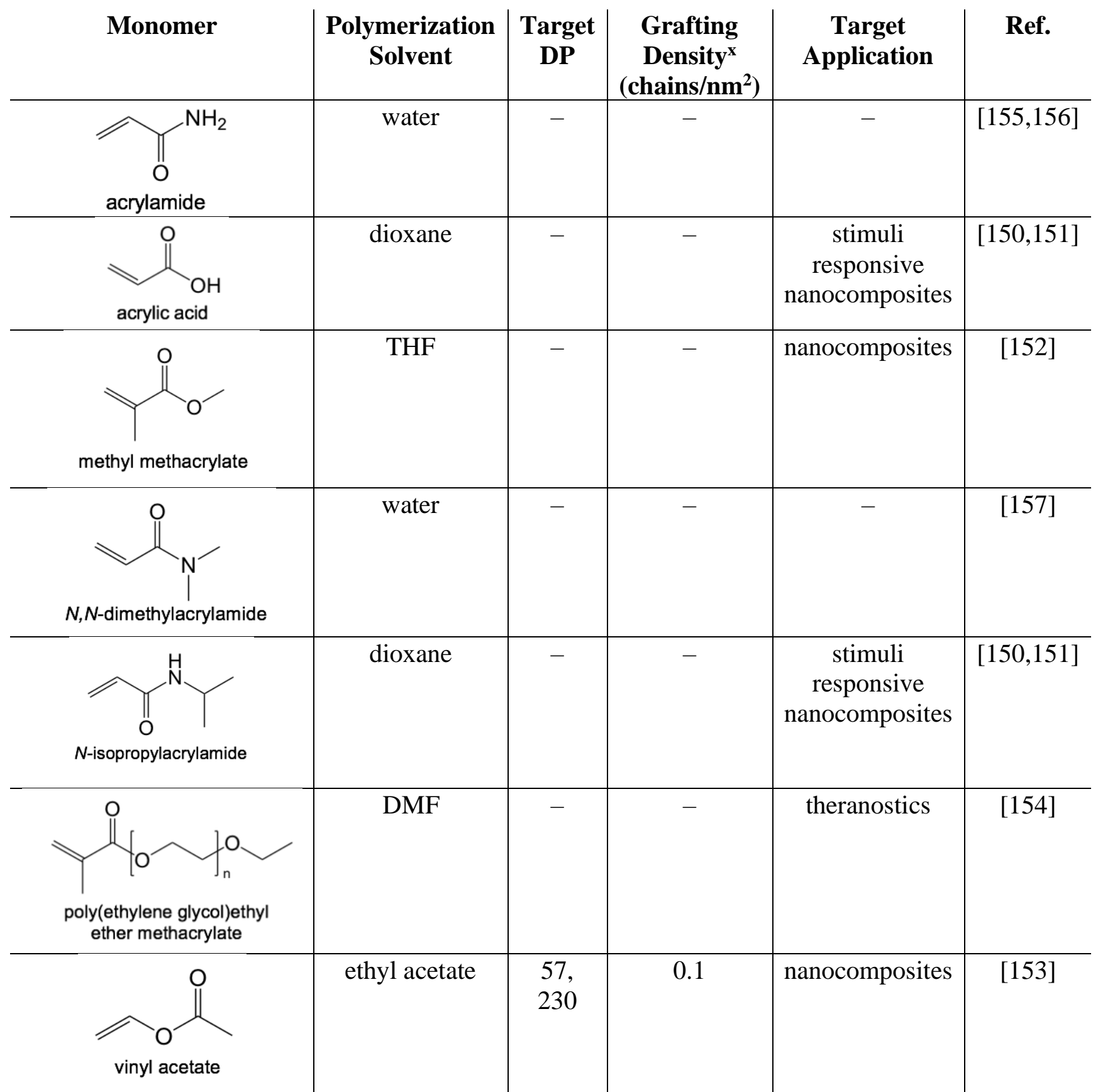

${ }^{\mathrm{x}}$ Grafting density was calculated based on the S content (where reported) based on ref [65] and assuming CNC dimensions of $120 \mathrm{~nm}$ in length and $15 \mathrm{~nm}$ in width and that all $\mathrm{S}$ sites were converted to polymer. 


\subsubsection{Nitroxide Mediated Polymerization}

Nitroxide mediated polymerization (NMP) is a form of CRP that relies on a reversible termination equilibrium between growing propagating macroradicals and the nitroxide moieties that act as control agents. This allows for the synthesis of well-defined polymeric structures from a variety of monomers such as styrene, acrylates, and methacrylates [116,158]. NMP is a simple polymerization method as it does not involve reversible redox processes or chain transfer reactions and is convenient to use in grafting from reactions with $\mathrm{CNCs}$, as the purification does not require the removal of transition metals. The major disadvantage is the typically lower polymerization rates, higher temperatures needed, and monomer limitations compared to other CRP techniques. To date, only a few examples of using NMP grafting from CNCs exist in the literature and are reported by Cunningham and coworkers who have grafted both hydrophilic and hydrophobic polymers.

Roeder et al. were the first to use NMP from CNCs to produce CNC- $g$-PMMA and CNC- $g$-PMA [159], shown in Figure 6. CNCs were treated with 4-(chloromethyl)styrene in DMSO, followed by $\quad N$-(2-methylpropyl)- $N$-(1-diethylphosphono-2,2-imethylpropyl)-O-(2-carboxylprop-2-yl) hydroxylamine (BlocBuilder ${ }^{\circledR}, \mathrm{BB}$ ) in $t$-butanol, then polymerized with methyl methacrylate or methacrylate. The polymer-grafted CNCs showed improved dispersion in organic solvents such as methanol, acetone, THF, and toluene. 


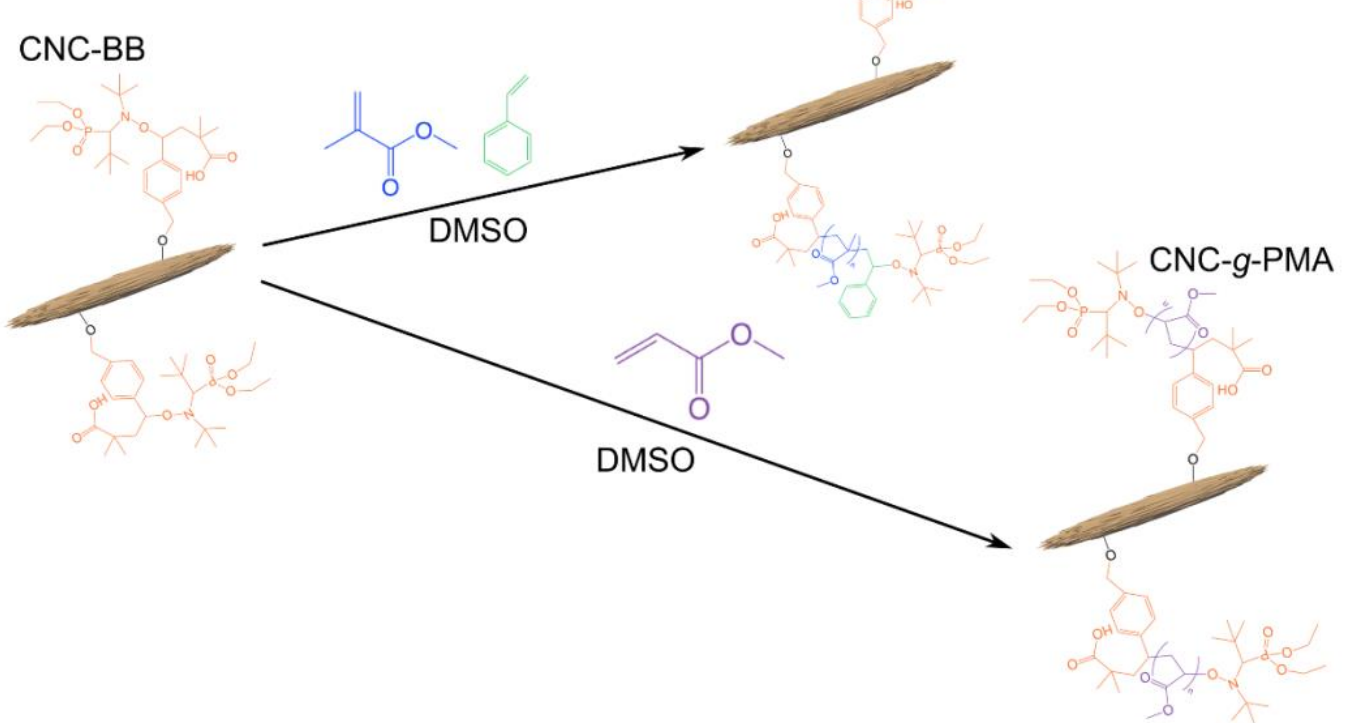

Figure 6. Example of using NMP to graft methyl methacrylate or methacrylate from BlocBuilder ${ }^{\circledR}$-modified CNCs (CNC-BB), adapted from reference [153].

NMP has also been used to graft $\mathrm{CO}_{2}$-responsive polymers from $\mathrm{CNCs}$. This was first reported by Garcia-Valdez et a. [160] who prepared BlocBuilder ${ }^{\circledR}$-modified CNCs using the same protocol as Roeder et al. [159]. They dispersed the initiator-modified CNCs in DMSO and polymerized switchable monomers such as 2-(dimethylamino)ethyl methacrylate, 2-(diethylamino)ethyl methacrylate, and $\mathrm{N}$-[3-(dimethylamino)propyl] methacrylamide with a small amount of styrene to improve control. The resulting polymer-grafted $\mathrm{CNCs}$ showed reversible $\mathrm{CO}_{2}$-responsiveness in water.

\section{Purification and Characterization of Polymer-grafted CNCs}

In order to fully understand the properties of polymer-grafted CNCs, the reaction product must be thoroughly purified before characterization in order to avoid characterizing excess reagents or free polymer that may be leftover or adsorbed to the CNC surface. Regardless of grafting method, purification is commonly done through centrifugation (where the modified CNCs are collected in the pellet and washed with solvent), dialysis to remove unreacted small molecules, stirred cell ultrafiltration, or Soxhlet extraction. These techniques become critical in the case of polymer grafting where homopolymer is present, since most characterization techniques cannot distinguish between covalently bound and adsorbed/trapped polymer. Furthermore, characterization 
difficulties arise when trying to distinguish between organic polymers and cellulose as they often have similar chemical moieties [129].

While a comprehensive list of suggested characterization methods for unmodified CNCs has recently been reported, with one section dedicated to characterizing functionalized cellulose nanomaterials [12], the list does not specifically address polymer-grafted CNCs. Important properties to characterize include polymer grafting density, graft length, polymer PDI, and initiator efficiency. The most common characterization techniques for polymer-grafted CNCs are water contact angle, elemental analysis, Fourier-transform infrared spectroscopy (FTIR), X-ray photoelectron spectroscopy (XPS), X-ray diffraction (XRD), nuclear magnetic resonance spectroscopy (NMR), thermal gravimetric analysis (TGA), and differential scanning calorimetry (DSC). To characterize free homopolymer, polymer synthesized from sacrificial initiator or polymers cleaved from $\mathrm{CNCs}$, traditional polymer characterization methods such as gel permeation chromatography (GPC) or NMR spectroscopy can be used.

The main methods to infer CNC surface modification after grafting is to examine the water contact angle of a dried CNC film or powder $[65,67,133,136,140,71,86,91,92,96,97,107,127]$ and to test colloidal stability of CNCs in non-aqueous solvents $[65,127]$. This provides indirect evidence that the grafting has been successful and that the hydrophilicity of CNCs has been changed. In order to probe the chemical composition, elemental analysis, FTIR, and XPS have been used extensively. Elemental analysis is a useful technique when the polymer-grafted CNCs contain an element different than carbon, hydrogen, or oxygen, which are found in unmodified CNCs. For example, if nitrogen containing monomers such as 4-vinylpyridine are grafted from CNCs, nitrogen is present in the polymer grafts such that elemental analysis to determine nitrogen content can be used to calculate the amount of polymer present. Similarly, if new chemical bonds are introduced, FTIR can play a useful role in identifying the presence of these new bonds [67]. For example, when grafting acrylate monomers from $\mathrm{CNCs}$, the presence of a carbonyl peak implies that polymer is present. XPS is another technique that can be used to confirm the presence of new elements, and furthermore can be used to collect high resolution carbon (C1s) or nitrogen (N1s) spectra. With high resolution carbon, the $\mathrm{C} 1 \mathrm{~s}$ spectra can differentiate between four typical carbon bonding environments: $\mathrm{C} 1$ (C-C, carbon bonded to only carbon), $\mathrm{C} 2$ (C-O-C, carbon bonded to one oxygen), $\mathrm{C} 3$ (O-C-O, carbon bonded to two oxygen), and $\mathrm{C} 4(\mathrm{O}-\mathrm{C}=\mathrm{O}$, carbon with three bonds 
to oxygen), which have different binding energies. Unmodified CNCs should only contain C2 and C3 (though $\mathrm{C} 1$ is always present due to contamination, so samples should be as pure as possible $[161,162])$, therefore the presence of $\mathrm{C} 4$ or an increase in $\mathrm{C} 1$ is often used to quantitatively determine the amount of polymer present [71].

XRD can be used to determine changes in crystallinity upon polymer grafting to or from CNCs. When CNCs are grafted with amorphous polymer, the \% crystallinity is expected to decrease for polymer-grafted CNCs, which has been shown in previous work [127]. The maintenance of the characteristic cellulose I peaks confirms that the CNC crystalline structure is retained during the modification reaction $[67,133]$ and that the decrease in crystallinity is due to the presence of amorphous polymer. Although the effects of preferred orientation of cellulose crystallites during sample processing must be taken into consideration when using XRD to quantify the amount of amorphous polymer in grafted CNCs, as the orientation of CNCs influences the calculation of \% crystallinity.

While NMR is the conventional "workhorse" of the synthetic polymer chemist, challenges arise when trying to analyze the chemical composition of CNCs and their derivatives. As CNCs cannot be dissolved in traditional NMR solvents (such as deuterated DMSO and deuterated chloroform), to the best of our knowledge there is only one report of using solution state NMR to characterize polymer-grafted CNCs. King et al. [163] used ionic liquids to dissolve PMMA-g-CNCs (prepared via free radical polymer grafting) and determine the polymer grafting density, after which methanolysis was performed in order to isolate the polymer grafts and determine their molecular weight through NMR self-diffusion measurements. This technique shows promise for quantifying polymer graft length and grafting density even for samples prepared via free radical polymerization that typically lack control over the polymerization kinetics [163].

Solid state NMR such as ${ }^{13} \mathrm{C}$-cross polarization magic angle spinning (CP-MAS) NMR shows potential for quantitative characterization of polymer-grafted CNCs and is performed on dried samples. In the 1980s, ${ }^{13} \mathrm{C}$ CP-MAS NMR was first used to determine the structure and crystallinity of native cellulose I [164,165], and in the 1990s, Heux et al. used the technique to study CNC structural aspects [166] and lateral dimensions [167]. It has recently been used to 
determine the degree of substitution of CNC modifications such as TEMPO oxidation [168], esterification [169], and polymer grafting [57,170], amongst others.

Polymer-grafted CNCs often display differences in thermal stability, which can be measured by TGA and DSC. TGA measures sample mass as a function of temperature and is used to determine the temperature at which a sample thermally degrades. Unmodified CNCs display a significant mass loss (and therefore thermal degradation) around $300^{\circ} \mathrm{C}$ [171]. A shift in thermal degradation temperature can be correlated to the presence of polymer or other small molecules. For example, after the attachment of ATRP initiators, the thermal degradation temperature of the CNCs decreases. This is attributed to the presence of the Br groups which may accelerate the degradation of the CNCs [126,127]. However, upon grafting polymer, the samples exhibit a secondary degradation peak that is shifted towards the onset of thermal degradation of the pure homopolymer, confirming the presence of polymer $[133,138]$. TGA can be used to determine the weight percent of polymer grafted based on the ratio of the secondary degradation peak attributed to the grafted polymer [127].

DSC is often used to determine the melting point and glass transition temperature $\left(T_{g}\right)$ of semicrystalline or amorphous polymers, respectively, so in the case of polymer-grafted CNCs, DSC is a way to characterize the polymer, but not the CNC itself. The $T_{g}$ is the temperature above which a hard "glassy" polymer transitions into a soft or rubbery polymer as the polymer chains have increased mobility [172]. An increase in the $T_{g}$ can imply a reduced mobility of the polymer, and in the case of polymer grafting, this implies that the polymer chains have been tethered to a surface. As such, an increase in the $T_{g}$ of the polymer has been used to support the covalent binding of polymers to the CNC surface $[127,133,173]$. Although DSC is beneficial in confirming the polymer is grafted on the CNC surface, it is typically qualitative and cannot determine specific polymer properties such as molecular weight.

\section{An Industrial Perspective of Polymer-grafted CNCs}

There is significant value in the academic work to date on polymer grafted-CNCs which, in general, is closely followed by industrial producers and potential end-users of cellulose nanomaterials. While the richness of scientific understanding that can be gained in the fields such as polymer chemistry, colloidal science, carbohydrate chemistry, and materials science is 
expansive, there are obvious concerns related to implementation costs that in many cases are restrictive for commercialization. In some of the best-case scenarios, costs of polymer-grafted CNCs reach hundreds of dollars per kilogram, which is high compared to commodity polymers and unmodified CNCs on their own. This, of course, would limit the use of polymer-grafted CNCs to specialized high value applications, such as pharmaceutical and biomedical products, or applications where extremely small amounts of material would be used, such as in retention or drainage aids for papermaking. Articulating the current limitations are not intended to limit the academic community but spur creativity and innovation by asking researchers to think about surface modification routes, scale-up and suitable applications in new ways (and to consider industrial consequences at earlier stages in the experimental design). One way to effectively use the "fine tuning" abilities of polymer grafting methods is in the design of model systems: for example, CRP grafting from CNCs can be used to systematically change CNC properties in order to link the effects such as hydrophobicity, colloidal stability, particle coverage, and surface roughness to compatibility/functionality in a given application. Once the critical surface properties have been identified and optimized through polymer grafting, researchers can look for alternative (lower cost) routes to achieve the same properties, such as through adsorption, small molecule modifications, or minor changes to the $\mathrm{CNC}$ production process.

The industrial interest in polymer-grafted CNCs is partially reflected by the fact that during this research and development stage, a number of international and US patents have been filed on their preparation and use. Cellulose nanomaterial producers watch for intellectual property generated by other companies, however, to date the patents remain primarily illustrative or defensive. Hamad and co-workers hold a number of early patents related to CNCs grafted with PLA via ROP (US 2011/0196094) [174], and CNCs grafted with hydrophobic vinyl monomers via free radical polymerization with CAN (US 8,349,948) [175] and the application of these materials in nanocomposites with enhanced gas barrier, rheological and mechanical performance. The preparation of thermoplastic and thermoset composites with polymer-grafted CNCs has also been patented for use as packaging materials, structural composites for automotive and construction applications, sandwiched foam composites or combined with biocompatible polymers in medical applications (WO 2013/037041 A1) [176]. Additionally and complementary to their published paper, Carlmark et al. patented the preparation of functional CNCs via acid hydrolysis which 
notably included attaching ATRP initiator functional groups during CNC production (WO 2014/070092 A1) [177]. More recently, Castro et al. patented adding CNCs grafted with polyacrylamide and poly(acrylic acid) to paper substrates for increased retention, wet and dry strength (WO 2015/050806 A1) [178] and Moghadam et al. patented polymer-grafted CNCs for use as rheological modifiers (WO 2017/066540 A1) [179]. As alluded to above, a patent does not imply that product development will follow, but it does support that those working in this field are interested in assessing possible value in such materials and proposing novel processes and applications.

\subsection{Manufacturing Considerations}

This section discusses key industrial considerations related to new process development, such as the scale up and implementation of polymer-grafted CNCs. Bringing a process to manufacturing readiness is a step that is often little considered initially in bringing a new process to fruition. It is frequently a significant challenge to find the reaction conditions that can allow a new product to be formed industrially. In the end, however, a process will remain of academic interest only if it is not taken through the steps needed for industrialization.

So what are the steps? It will depend on the particular process that is being considered but in this review the focus is on modifying the surface of CNCs to make them compatible with a wider range of media. The high level steps in this case are:

1. Determine the value of the proposed modification in the targeted application

2. Determine if the cost of the production will maintain the value in the application

3. Assess the safety, environmental and regulatory requirements of the new product Step 1 requires identification of the value proposition for the modification. In which system or systems will a given modification be used? What will the improvement in properties be? Does the improvement address the need of an industrial partner at an acceptable cost? Is there a committed industrial partner? Answers to these questions will allow the move to Step 2.

Step 2 at first glance seems simple in that it is taking the reaction that is being done on the bench and using the same process, conditions and larger equipment to make larger quantities. In most instances, however, it would immediately fail Step 1. At the beginning it is essential to choose between competing processes for achieving the goal and consider the potential for integration into 
present manufacturing processes. How many steps does the process have? What solvents are being used in the process? What temperatures and times are being used in the process? What purification steps are required? What is the toxicology of the materials used in the manufacturing process? In the best of situations, the answer to these questions would be one, water, room temperature, instant, no purification and toxicologically benign. In addition, control of the process to provide a uniform product is essential. In the majority of proposed reaction schemes, many of these preferred parameters are not met and therefore the requirement in Step 1 becomes ever more challenging and the discussion with the industrial partner becomes more critical.

Even if Steps 1 and 2 are passed, Step 3 is essential. Many dollars were spent on the regulatory assessment of unmodified CNCs. Every modification to the surface represents a new material and a toxicological evaluation is needed with each type of modification. As well, impurities such as solvent and catalyst traces can remain that add further challenges to the eventual acceptance of the material by an industrial partner and the end-user. Included in Step 3 is the safety and environmental elements of the process. This consideration is married to the toxicological requirement and choices can be made, if solvents are required, as to the toxicological class to which they belong.

The principle of Occam's razor (that the simplest solution tends to be the best one) is often properly applied to hypotheses, but it can equally well be applied to processes and manufacturing, simpler is more likely to be successful!

\section{Conclusions and Outlook}

Polymer grafting to and from $\mathrm{CNCs}$ are sophisticated methods to prepare functional CNCs with novel properties, as evidenced by the many reports in the literature over the past decade. The wide variety of techniques provide a range of benefits and pitfalls, and when deciding on a technique to use, the reader is encouraged to consider the type of polymer (hydrophilic vs. hydrophobic), number of reaction steps, purification requirements, and control and tunability of polymer properties needed.

Polymer grafting to is useful when a pre-formed polymer with known molecular weight is of importance or the end-functionalized polymer is available commercially (and cheaply) or is 
straightforward to synthesize. However, high grafting density is difficult to achieve, and extensive purification is required to remove unreacted polymer. Additionally, quantification of graft density is difficult to characterize and rarely reported. This method is best used for niche applications where high grafting density is not crucial.

Polymer grafting from via free radical polymerization is a facile technique to modify CNCs with both hydrophilic and moderately hydrophobic polymers. The reactions are performed in aqueous environments where CNCs are colloidally stable, and there is no need to attach initiators, making this a one-step, and potentially more industrially feasible process. Free radical polymerization from CNCs also provides the opportunity to prepare CNC-polymer nanocomposites in situ, where purification to remove homopolymer can be omitted.

Finally, polymer grafting from CNCs using CRP provides control over both the polymer graft length and grafting density. This is the most complicated technique of grafting from $\mathrm{CNCs}$ and is often a multi-step process with lengthy purification. Reactions are always performed in solvents in which dispersing CNCs is a known issue, and as of yet, the uniformity of individual nanoparticle modification has not been determined experimentally. This technique should likely be reserved for model studies and specialty applications, recognizing that there are various set-backs when it comes to scale-up and cost feasibility. However, CRP allows for the systematic evaluation of graft length and grafting density, initiator efficiency, and polymer kinetics and can therefore be optimized to suit a range of academic/industrial needs. Furthermore, for high value application (such as biomedical applications) precise control and purity are crucial factors and cost may be less of a concern.

As fundamental and applied cellulose nanomaterial research continues to grow, grafting polymers to or from $\mathrm{CNC}$ surfaces remain one promising method amongst a "toolbox" of modification routes for providing improved compatibility between CNCs and their environments. For applicationdriven research we stress that it is important to consider the challenges of industrialization at early stages, specifically scale-up, toxicology and costs. While strong scientific foundations have been laid in this field, good industrial interaction is essential to advance the development of modified cellulose nanomaterial-based products. 


\section{Acknowledgements}

SK acknowledges the support of the Natural Sciences and Engineering Research Council of Canada (NSERC) in the form of a NSERC Postdoctoral Fellowship. EC is grateful to NSERC for financial support (Discovery Grants RGPIN-2017-05252) and holds the Canada Research Chair (Tier 2) in Bio-based Nanomaterials. JZ is grateful for the financial support from the Swiss National Science Foundation (SNSF) (Ambizione Grant no. PZ00P2_167900) and the Adolphe Merkle Foundation. 


\section{References}

[1] P.T. Anastas, J.C. Warner, Green Chemistry: Theory and Practice, Oxford University Press, New York, 1998.

[2] R.F. Nickerson, J.A. Habrle, Cellulose Intercrystalline Structure, Ind. Eng. Chem. 39 (1947) 1507-1512.

[3] S.J. Hanley, J. Giasson, J. Revol, D.G. Gray, Atomic force microscopy of cellulose microfibrils: comparison with transmission electron microscopy, Polymer (Guildf). 33 (1992) 4639-4642.

[4] X.M. Dong, T. Kimura, J.-F. Revol, D.G. Gray, Effects of Ionic Strength on the Isotropic-Chiral Nematic Phase Transition of Suspensions of Cellulose Crystallites, Langmuir. 12 (1996) 2076-2082.

[5] J.F. Revol, L. Godbout, D.G. Gray, Solid self-assembled films of cellulose with chiral nematic order and optically variable properties, J. Pulp Pap. Sci. 24 (1998) 146-149.

[6] V. Favier, H. Chanzy, J.Y. Cavaillé, Polymer Nanocomposites Reinforced by Cellulose Whiskers, Macromolecules. 28 (1995) 6365-6367.

[7] Y. Habibi, L.A. Lucia, O.J. Rojas, Cellulose Nanocrystals: Chemistry, Self-Assembly, and Applications, Chem. Rev. 110 (2010) 3479-3500.

[8] Y. Habibi, Key Advances in the Chemical Modification of Nanocelluloses, Chem. Soc. Rev. 43 (2014) 1519-42.

[9] D. Klemm, F. Kramer, S. Moritz, T. Lindström, M. Ankerfors, D. Gray, A. Dorris, Nanocelluloses: A New Family of Nature-Based Materials, Angew. Chemie Int. Ed. 50 (2011) 5438-5466.

[10] H. Oguzlu, C. Danumah, Y. Boluk, Colloidal behavior of aqueous cellulose nanocrystal suspensions, Curr. Opin. Colloid Interface Sci. 29 (2017) 46-56.

[11] C. Salas, T. Nypelö, C. Rodriguez-Abreu, C. Carrillo, O.J. Rojas, Nanocellulose Properties and Applications in Colloids and Interfaces, Curr. Opin. Colloid Interface Sci. 19 (2014) 383-396.

[12] E.J. Foster, R.J. Moon, U.P. Agarwal, M.J. Bortner, J. Bras, S. Camarero-Espinosa, K.J. Chan, M.J.D. Clift, E.D. Cranston, S.J. Eichhorn, D.M. Fox, W.Y. Hamad, L. Heux, B. Jean, M. Korey, W. Nieh, K.J. Ong, M.S. Reid, S. Renneckar, R. Roberts, J.A. Shatkin, J. Simonsen, K. Stinson-Bagby, N. Wanasekara, J. Youngblood, Current characterization methods for cellulose nanomaterials, Chem. Soc. Rev. 47 (2018) 2609-2679.

[13] J. Tang, J. Sisler, N. Grishkewich, K.C. Tam, Functionalization of cellulose nanocrystals for advanced applications, J. Colloid Interface Sci. 494 (2017) 397-409.

[14] N. Grishkewich, N. Mohammed, J. Tang, K.C. Tam, Recent Advances in the Application of Cellulose Nanocrystals, Curr. Opin. Colloid Interface Sci. 99 (2017) 537-552.

[15] A. Dufresne, Cellulose Nanomaterial Reinforced Polymer Nanocomposites, Curr. Opin. Colloid Interface Sci. 29 (2017) 1-8.

[16] D. Klemm, E.D. Cranston, D. Fischer, M. Gama, S.A. Kedzior, D. Kralisch, F. Kramer, T. Kondo, T. Lindström, S. Nietzsche, K. Petzold-Welcke, F. Rauchfuß, Nanocellulose as a natural source for groundbreaking applications in materials science: Today's state, Mater. Today. 21 (2018) 720-748.

[17] S. Beck-Candanedo, M. Roman, D. Gray, Effect of Reaction Conditions on the Properties Behavior of Wood Cellulose Nanocrystals Suspensions, Biomacromolecules. 6 (2005) 1048-1054.

[18] T.S. Anirudhan, S.R. Rejeena, Poly(acrylic acid)-modified poly(glycidylmethacrylate)- 
grafted nanocellulose as matrices for the adsorption of lysozyme from aqueous solutions, Chem. Eng. J. 187 (2012) 150-159.

[19] A. Benkaddour, K. Jradi, S. Robert, C. Daneault, Study of the Effect of Grafting Method on Surface Polarity of Tempo-Oxidized Nanocellulose Using Polycaprolactone as the Modifying Compound: Esterification versus Click-Chemistry, Nanomaterials. 3 (2013) 638-654.

[20] T.S. Anirudhan, S.R. Rejeena, Poly(methacrylic acid-co-vinyl sulfonic acid)-graftedmagnetite/ nanocellulose superabsorbent composite for the selective recovery and separation of immunoglobulin from aqueous solutions, Sep. Purif. Technol. 119 (2013) 82-93.

[21] Z. Song, H. Xiao, Y. Zhao, Hydrophobic-modified nano-cellulose fiber/PLA biodegradable composites for lowering water vapor transmission rate (WVTR) of paper, Carbohydr. Polym. 111 (2014) 442-448.

[22] F. Zhang, W. Wu, X. Zhang, X. Meng, G. Tong, Y. Deng, Temperature-sensitive polyNIPAm modified cellulose nanofibril cryogel microspheres for controlled drug release, Cellulose. 23 (2016) 415-425.

[23] B. Wei, H. Li, Q. Li, Y. Wen, L. Sun, P. Wei, W. Pu, Y. Li, Stabilization of Foam Lamella Using Novel Surface-Grafted Nanocellulose-Based Nanofluids, Langmuir. 33 (2017) 5127-5139.

[24] A.C.W. Leung, S. Hrapovic, E. Lam, Y. Liu, K.B. Male, K.A. Mahmoud, J.H.T. Luong, Characteristics and properties of carboxylated cellulose nanocrystals prepared from a novel one-step procedure, Small. 7 (2011) 302-305.

[25] Y. Habibi, H. Chanzy, M.R. Vignon, TEMPO-mediated surface oxidation of cellulose whiskers, Cellulose. 13 (2006) 679-687.

[26] I. Kalashnikova, H. Bizot, B. Cathala, I. Capron, Modulation of Cellulose Nanocrystals Amphiphilic Properties to Stabilize Oil/Water Interface, Biomacromolecules. 13 (2012) 267-275.

[27] I. Kalashnikova, H. Bizot, B. Cathala, I. Capron, New Pickering Emulsions Stabilized by Bacterial Cellulose Nanocrystals, Langmuir. 27 (2011) 7471-7479.

[28] S. Beck, J. Bouchard, R. Berry, Dispersibility in Water of Dried Nanocrystalline Cellulose, Biomacromolecules. 13 (2012) 1486-94.

[29] F. Cherhal, F. Cousin, I. Capron, Influence of charge density and ionic strength on the aggregation process of cellulose nanocrystals in aqueous suspension, as revealed by smallangle neutron scattering, Langmuir. 31 (2015) 5596-602.

[30] H. Wang, C. Qian, M. Roman, Effects of $\mathrm{pH}$ and salt concentration on the formation and properties of chitosan-cellulose nanocrystal polyelectrolyte-macroion complexes, Biomacromolecules. 12 (2011) 3708-3714.

[31] S. Beck, J. Bouchard, Auto-catalyzed acidic desulfation of cellulose nanocrystals, Nord. Pulp Pap. Res. J. 29 (2014) 6-14.

[32] M. Hasani, E.D. Cranston, G. Westman, D.G. Gray, Cationic Surface Functionalization of Cellulose Nanocrystals, Soft Matter. 4 (2008) 2238-2244.

[33] D. Viet, S. Beck-Candanedo, D.G. Gray, Dispersion of Cellulose Nanocrystals in Polar Organic Solvents, Cellulose. 14 (2007) 109-113.

[34] O. van der Berg, J.R. Capadona, C. Weder, Preparation of homogeneous dispersions of tunicate cellulose whiskers in organic solvents, Biomacromolecules. 8 (2007) 1353-1357.

[35] E. Kontturi, A. Meriluoto, P.A. Penttilä, N. Baccile, J.-M. Malho, A. Potthast, T. Rosenau, 
J. Ruokolainen, R. Serimaa, J. Laine, H. Sixta, Degradation and Crystallization of Cellulose in Hydrogen Chloride Vapor for High-Yield Isolation of Cellulose Nanocrystals, Angew. Chemie Int. Ed. 55 (2016) 14455-14458.

[36] E. Kloser, D.G. Gray, Surface grafting of cellulose nanocrystals with poly(ethylene oxide) in aqueous media, Langmuir. 26 (2010) 13450-13456.

[37] J. Araki, Electrostatic or steric?-preparations and characterizations of well-dispersed systems containing rod-like nanowhiskers of crystalline polysaccharides, Soft Matter. 9 (2013) 4125-4141.

[38] M.S. Reid, M. Villalobos, E.D. Cranston, Benchmarking Cellulose Nanocrystals: From the Laboratory to Industrial Production, Langmuir. 33 (2017) 1583-1598.

[39] R.M.A. Domingues, M.E. Gomes, R.L. Reis, The Potential of Cellulose Nanocrystals in Tissue Engineering Strategies, Biomacromolecules. 15 (2014) 2327-2346.

[40] V. Lafitte, Application of Cellulose Nanocrystals in Oilfield Gravel Packing Fluid, in: Tech. Assoc. Pulp Pap. Inst. Nanotechnol. Div., Montreal, 2017.

[41] Y. Habibi, I. Hoeger, S.S. Kelley, O.J. Rojas, Development of Langmuir-Schaeffer Cellulose Nanocrystal Monolayers and Their Interfacial Behaviors, Langmuir. 26 (2010) 990-1001.

[42] N. Dhar, D. Au, R.C. Berry, K.C. Tam, Interactions of Nanocrystalline Cellulose with an Oppositely Charged Surfactant in Aqueous Medium, Colloids Surfaces A Physicochem. Eng. Asp. 415 (2012) 310-319.

[43] C. Brinatti, J. Huang, R.M. Berry, K.C. Tam, W. Loh, Structural and Energetic Studies on the Interaction of Cationic Surfactants and Cellulose Nanocrystals, Langmuir. 32 (2016) 689-698.

[44] M. Salajkova, L.A. Berglund, Q. Zhou, Hydrophobic Cellulose Nanocrystals Modified with Quaternary Ammonium Salts, J. Mater. Chem. 22 (2012) 19798.

[45] T. Abitbol, H. Marway, E.D. Cranston, Surface Modification of Cellulose Nanocrystals with Cetyltrimethylammonium Bromide, Nord. Pulp Pap. Res. J. 29 (2014) 46-57.

[46] A. Kaboorani, B. Riedl, Surface Modification of Cellulose Nanocrystals (CNC) by a Cationic Surfactant, Ind. Crops Prod. 65 (2015) 45-55.

[47] G. Morandi, W. Thielemans, Synthesis of Cellulose Nanocrystals Bearing Photocleavable Grafts by ATRP, Polym. Chem. 3 (2012) 1402-1407.

[48] J. Araki, M. Wada, S. Kuga, Steric stabilization of a cellulose microcrystal suspension by poly(ethylene glycol) grafting, Langmuir. 17 (2001) 21-27.

[49] V. Mano, S. Chimenti, G. Ruggeri, F.V. Pereira, E.L. de Paula, P(CL-b-LLA) diblock copolymers grafting onto cellulosic nanocrystals, Polym. Bull. 74 (2017) 3673-3688.

[50] V. Kupka, Q. Zhou, F. Ansari, H. Tang, M. Šlouf, L. Vojtová, L.A. Berglund, J. Jančáŕ, Well-dispersed polyurethane/cellulose nanocrystal nanocomposites synthesized by a solvent-free procedure in bulk, Polym. Compos. (2018).

[51] S. Harrisson, G.L. Drisko, E. Malmström, A. Hult, K.L. Wooley, Hybrid rigid/soft and biologic/synthetic materials: Polymers grafted onto cellulose microcrystals, Biomacromolecules. 12 (2011) 1214-1223.

[52] Z.Q. Li, X.D. Zhou, C.H. Pei, Synthesis of PLA-co-PGMA copolymer and its application in the surface modification of bacterial cellulose, Int. J. Polym. Mater. Polym. Biomater. 59 (2010) 725-737.

[53] Y. Habibi, A. Dufresne, Highly filled bionanocomposites from functionalized polysaccharides nanocrystals, Biomacromolecules. 9 (2008) 1974-1980. 
[54] X. Cao, Y. Habibi, L. Lucia, One-pot polymerization, surface grafting, and processing of waterborne polyurethane-cellulose nanocrystal nanocomposites, J. Mater. Chem. 19 (2009) 7137.

[55] A. Pei, J.M. Malho, J. Ruokolainen, Q. Zhou, L.A. Berglund, Strong nanocomposite reinforcement effects in polyurethane elastomer with low volume fraction of cellulose nanocrystals, Macromolecules. 44 (2011) 4422-4427.

[56] A.P. Mangalam, J. Simonsen, A.S. Benight, Cellulose/DNA Hybrid Nanomaterials, Biomacromolecules. 10 (2009) 497-504.

[57] F. Azzam, L. Heux, J.-L. Putaux, B. Jean, Preparation By Grafting Onto, Characterization, and Properties of Thermally Responsive Polymer-Decorated Cellulose Nanocrystals, Biomacromolecules. 11 (2010) 3652-3659.

[58] F. Azzam, E. Siqueira, S. Fort, R. Hassaini, F. Pignon, C. Travelet, J.L. Putaux, B. Jean, Tunable Aggregation and Gelation of Thermoresponsive Suspensions of Polymer-Grafted Cellulose Nanocrystals, Biomacromolecules. 17 (2016) 2112-2119.

[59] N. Ljungberg, C. Bonini, F. Bortolussi, C. Boisson, L. Heux, J.Y. Cavaillé, New nanocomposite materials reinforced with cellulose whiskers in atactic polypropylene: Effect of surface and dispersion characteristics, Biomacromolecules. 6 (2005) 2732-2739.

[60] H. Rosilo, E. Kontturi, J. Seitsonen, E. Kolehmainen, O. Ikkala, Transition to reinforced state by percolating domains of intercalated brush-modified cellulose nanocrystals and poly(butadiene) in cross-linked composites based on thiol-ene click chemistry, Biomacromolecules. 14 (2013) 1547-1554.

[61] Y. Habibi, A. Dufresne, Highly filled bionanocomposites from functionalized polysaccharide nanocrystals, Biomacromolecules. 9 (2008) 1974-1980.

[62] L. Zhou, H. He, M.C. Li, S. Huang, C. Mei, Q. Wu, Grafting polycaprolactone diol onto cellulose nanocrystals via click chemistry: Enhancing thermal stability and hydrophobic property, Carbohydr. Polym. 189 (2018) 331-341.

[63] A. Fatona, R.M. Berry, M.A. Brook, J.M. Moran-Mirabal, Versatile Surface Modification of Cellulose Fibers and Cellulose Nanocrystals through Modular Triazinyl Chemistry, Chem. Mater. 30 (2018) 2424-2435.

[64] J. Glasing, J. Bouchard, P.G. Jessop, P. Champagne, M.F. Cunningham, Grafting welldefined $\mathrm{CO} 2$-responsive polymers to cellulose nanocrystals via nitroxide-mediated polymerisation: Effect of graft density and molecular weight on dispersion behaviour, Polym. Chem. 8 (2017) 6000-6012.

[65] S.A. Kedzior, M. Kiriakou, E. Niinivaara, M.A. Dubé, C. Fraschini, R.M. Berry, E.D. Cranston, Incorporating Cellulose Nanocrystals into the Core of Polymer Latex Particles via Polymer Grafting, ACS Macro Lett. (2018) 990-996.

[66] J. Glasing, P. Champagne, M.F. Cunningham, Graft modification of chitosan, cellulose and alginate using reversible deactivation radical polymerization (RDRP), Curr. Opin. Green Sustain. Chem. 2 (2016) 15-21.

[67] G. Morandi, L. Heath, W. Thielemans, Cellulose Nanocrystals Grafted with Polystyrene Chains Through Surface-Initiated Atom Transfer Radical Polymerization (SI-ATRP), Langmuir. 25 (2009) 8280-8286.

[68] K.H.M. Kan, J. Li, K. Wijesekera, E.D. Cranston, Polymer-Grafted Cellulose Nanocrystals as pH-Responsive Reversible Flocculants, Biomacromolecules. 14 (2013) 3130-3139.

[69] M. Pracella, M.M.U. Haque, D. Puglia, Morphology and Properties Tuning of 
PLA/Cellulose Nanocrystals Bio-Nanocomposites by Means of Reactive Functionalization and Blending with PVAc, Polymer (Guildf). 55 (2014) 3720-3728.

[70] J. Tang, R.M. Berry, K.C. Tam, Stimuli-Responsive Cellulose Nanocrystals for Surfactant-Free Oil Harvesting, Biomacromolecules. 17 (2016) 1748-1756.

[71] S.A. Kedzior, L. Graham, C. Moorlag, B.M. Dooley, E.D. Cranston, Poly(methyl methacrylate)-Grafted Cellulose Nanocrystals: One-step Synthesis, Nanocomposite Preparation, and Characterization, Can. J. Chem. Eng. 94 (2016) 811-822.

[72] B. Li, Y. Zhang, C. Wu, B. Guo, Z. Luo, Fabrication of mechanically tough and selfrecoverable nanocomposite hydrogels from polyacrylamide grafted cellulose nanocrystal and poly(acrylic acid), Carbohydr. Polym. 198 (2018) 1-8.

[73] C. Zhou, Q. Wu, Q. Zhang, Dynamic Rheology Studies of in situ Polymerization Process of Polyacrylamide-Cellulose Nanocrystal Composite Hydrogels, Colloid Polym. Sci. 289 (2011) 247-255.

[74] C. Zhou, Q. Wu, Y. Yue, Q. Zhang, Application of Rod-Shaped Cellulose Nanocrystals in Polyacrylamide Hydrogels, J. Colloid Interface Sci. 353 (2011) 116-123.

[75] J. Yang, C.R. Han, J.F. Duan, M.G. Ma, X.M. Zhang, F. Xu, R.C. Sun, Synthesis and characterization of mechanically flexible and tough cellulose nanocrystals-polyacrylamide nanocomposite hydrogels, Cellulose. 20 (2013) 227-237.

[76] J. Yang, C.-R. Han, J.-F. Duan, M.-G. Ma, X.-M. Zhang, F. Xu, R.-C. Sun, X.-M. Xie, Studies on the Properties and Formation Mechanism of Flexible Nanocomposite Hydrogels from Cellulose Nanocrystals and Poly(acrylic acid), J. Mater. Chem. 22 (2012) 22467-22480.

[77] Y. Wu, L. Wang, Y. Qing, N. Yan, C. Tian, Y. Huang, A green route to prepare fluorescent and absorbent nano-hybrid hydrogel for water detection, Sci. Rep. 7 (2017) 111.

[78] T.S. Anirudhan, S.R. Rejeena, J. Binusree, Adsorptive separation of myoglobin from aqueous solutions using iron oxide magnetic nanoparticles modified with functionalized nanocrystalline cellulose, J. Chem. Eng. Data. 58 (2013) 1329-1339.

[79] S. Liu, M. Jin, Y. Chen, H. Gao, X. Shi, W. Cheng, L. Ren, Y. Wang, High internal phase emulsions stabilised by supramolecular cellulose nanocrystals and their application as cell-adhesive macroporous hydrogel monoliths, J. Mater. Chem. B. 5 (2017) 2671-2678.

[80] E. Espino-Pérez, R.G. Gilbert, S. Domenek, M.C. Brochier-Salon, M.N. Belgacem, J. Bras, Nanocomposites with functionalised polysaccharide nanocrystals through aqueous free radical polymerisation promoted by ozonolysis, Carbohydr. Polym. 135 (2016) 256266.

[81] J. Tang, M.F.X. Lee, W. Zhang, B. Zhao, R.M. Berry, K.C. Tam, Dual responsive pickering emulsion stabilized by poly[2-(dimethylamino) ethyl methacrylate] grafted cellulose nanocrystals, Biomacromolecules. 15 (2014) 3052-3060.

[82] K. Zubik, P. Singhsa, Y. Wang, H. Manuspiya, R. Narain, Thermo-responsive poly(Nisopropylacrylamide)-cellulose nanocrystals hybrid hydrogels for wound dressing, Polymers (Basel). 9 (2017).

[83] J. Wang, G. Siqueira, G. Müller, D. Rentsch, A. Huch, P. Tingaut, J. LevaloisGrützmacher, H. Grützmacher, Synthesis of new bis(acyl)phosphane oxide photoinitiators for the surface functionalization of cellulose nanocrystals, Chem. Commun. 52 (2016) 2823-2826.

[84] M. Kalantari, R. Du, C. Ayranci, Y. Boluk, Effects of interfacial interactions and 
interpenetrating brushes on the electrospinning of cellulose nanocrystals-polystyrene fibers, J. Colloid Interface Sci. 528 (2018) 419-430.

[85] A. Carlmark, E. Larsson, E. Malmström, Grafting of cellulose by ring-opening polymerisation - A review, Eur. Polym. J. 48 (2012) 1646-1659.

[86] Y. Habibi, A.L. Goffin, N. Schiltz, E. Duquesne, P. Dubois, A. Dufresne, Bionanocomposites based on poly( $\varepsilon$-caprolactone)-grafted cellulose nanocrystals by ringopening polymerization, J. Mater. Chem. 18 (2008) 5002-5010.

[87] M. Labet, W. Thielemans, Improving the Reproducibility of Chemical Reactions on the Surface of Cellulose Nanocrystals: ROP of $\varepsilon$-caprolactone as a Case Study, Cellulose. 18 (2011) 607-617.

[88] N. Lin, G. Chen, J. Huang, A. Dufresne, P.R. Chang, Effects of Polymer-Grafted Natural Nanocrystals on the Structure and Mechanical Properties of Poly(lactic acid): A Case of Cellulose Whisker-Graft-Polycaprolactone, J. Appl. Polym. Sci. 113 (2009) 3417-3425.

[89] A.-L. Goffin, J.-M. Raquez, E. Duquesne, G. Siqueira, Y. Habibi, A. Dufresne, P. Dubois, Poly( $\varepsilon$-caprolactone) Based Nanocomposites Reinforced by Surface-Grafted Cellulose Nanowhiskers via Extrusion Processing: Morphology, Rheology, and Thermo-Mechanical Properties, Polymer (Guildf). 52 (2011) 1532-1538.

[90] A.L. Goffin, Y. Habibi, J.M. Raquez, P. Dubois, Polyester-grafted cellulose nanowhiskers: A new approach for tuning the microstructure of immiscible polyester blends, ACS Appl. Mater. Interfaces. 4 (2012) 3364-3371.

[91] C. Tian, S. Fu, J. Chen, Q. Meng, L.A. Lucia, Graft polymerization of epsiloncaprolactone to cellulose nanocrystals and optimization of grafting conditions utilizing a response surface methodology, Nord. Pulp Pap. Res. J. 29 (2014) 58-68.

[92] C. Tian, S. Fu, Y. Habibi, L.A. Lucia, Polymerization topochemistry of cellulose nanocrystals: A function of surface dehydration control, Langmuir. 30 (2014) 14670_ 14679.

[93] C.F. Bellani, E. Pollet, A. Hebraud, F. V. Pereira, G. Schlatter, L. Avérous, R.E.S. Bretas, M.C. Branciforti, Morphological, thermal, and mechanical properties of poly $(\varepsilon-$ caprolactone)/poly( $\varepsilon$-caprolactone)-grafted-cellulose nanocrystals mats produced by electrospinning, J. Appl. Polym. Sci. 133 (2016) 4-11.

[94] J.K. Muiruri, S. Liu, W.S. Teo, J. Kong, C. He, Highly Biodegradable and Tough Polylactic Acid-Cellulose Nanocrystal Composite, ACS Sustain. Chem. Eng. 5 (2017) 3929-3937.

[95] J.A. Simão, C.F. Bellani, M.C. Branciforti, Thermal properties and crystallinity of PCL/PBSA/cellulose nanocrystals grafted with PCL chains, J. Appl. Polym. Sci. 134 (2017) 1-9.

[96] G. Chen, A. Dufresne, J. Huang, P.R. Chang, A Novel Thermoformable Bionanocomposite Based on Cellulose Nanocrystal-graft-Poly( $\varepsilon$-caprolactone), Macromol. Mater. Eng. 294 (2009) 59-67.

[97] M. Labet, W. Thielemans, Citric acid as a benign alternative to metal catalysts for the production of cellulose-grafted-polycaprolactone copolymers, Polym. Chem. 3 (2012) 679-684.

[98] V. Sessini, I. Navarro-Baena, M.P. Arrieta, F. Dominici, D. López, L. Torre, J.M. Kenny, P. Dubois, J.M. Raquez, L. Peponi, Effect of the addition of polyester-grafted-cellulose nanocrystals on the shape memory properties of biodegradable PLA/PCL nanocomposites, Polym. Degrad. Stab. 152 (2018) 126-138. 
[99] A.L. Goffin, J.M. Raquez, E. Duquesne, G. Siqueira, Y. Habibi, A. Dufresne, P. Dubois, From interfacial ring-opening polymerization to melt processing of cellulose nanowhisker-filled polylactide-based nanocomposites, Biomacromolecules. 12 (2011) 2456-2465.

[100] B. Braun, J.R. Dorgan, L.O. Hollingsworth, Supra-molecular ecobionanocomposites based on polylactide and cellulosic nanowhiskers: synthesis and properties.,

Biomacromolecules. 13 (2012) 2013-2019.

[101] N. Bitinis, R. Verdejo, J. Bras, E. Fortunati, J.M. Kenny, L. Torre, M.A. LopezManchado, Poly(lactic acid)/natural rubber/cellulose nanocrystal bionanocomposites Part I. Processing and morphology, Carbohydr. Polym. 96 (2013) 611-620.

[102] M. Peltzer, A. Pei, Q. Zhou, L. Berglund, A. Jiménez, Surface modification of cellulose nanocrystals by grafting with poly(lactic acid), Polym. Int. 63 (2014) 1056-1062.

[103] P. Ma, L. Jiang, P. Xu, W. Dong, M. Chen, P.J. Lemstra, Rapid Stereocomplexation between Enantiomeric Comb-Shaped Cellulose-g-poly(l-lactide) Nanohybrids and Poly(dlactide) from the Melt, Biomacromolecules. 16 (2015) 3723-3729.

[104] E. Lizundia, J.L. Vilas, L.M. León, Crystallization, structural relaxation and thermal degradation in Poly(l-lactide)/cellulose nanocrystal renewable nanocomposites, Carbohydr. Polym. 123 (2015) 256-265.

[105] E.L. de Paula, F. Roig, A. Mas, J.P. Habas, V. Mano, F.V. Pereira, J.J. Robin, Effect of surface-grafted cellulose nanocrystals on the thermal and mechanical properties of PLLA based nanocomposites, Eur. Polym. J. 84 (2016) 173-187.

[106] E. Lizundia, E. Fortunati, F. Dominici, J.L. Vilas, L.M. León, I. Armentano, L. Torre, J.M. Kenny, PLLA-grafted cellulose nanocrystals: Role of the CNC content and grafting on the PLA bionanocomposite film properties, Carbohydr. Polym. 142 (2016) 105-113.

[107] C. Miao, W.Y. Hamad, In-situ polymerized cellulose nanocrystals (CNC) - poly(Llactide) (PLLA) nanomaterials and applications in nanocomposite processing, Carbohydr. Polym. 153 (2016) 549-558.

[108] N. Bitinis, E. Fortunati, R. Verdejo, J. Bras, J.M. Kenny, L. Torre, M.A. LópezManchado, Poly(lactic acid)/natural rubber/cellulose nanocrystal bionanocomposites Part II. Properties evaluation, Carbohydr. Polym. 96 (2013) 621-627.

[109] Y. Habibi, S. Aouadi, J.M. Raquez, P. Dubois, Effects of interfacial stereocomplexation in cellulose nanocrystal-filled polylactide nanocomposites, Cellulose. 20 (2013) 2877-2885.

[110] P. Ma, T. Shen, L. Lin, W. Dong, M. Chen, Cellulose-g-poly(D-lactide) nanohybrids induced significant low melt viscosity and fast crystallization of fully bio-based nanocomposites, Carbohydr. Polym. 155 (2017) 498-506.

[111] H. Wu, S. Nagarajan, L. Zhou, Y. Duan, J. Zhang, Synthesis and characterization of cellulose nanocrystal-graft-poly(D-lactide) and its nanocomposite with poly(L-lactide), Polymer (Guildf). 103 (2016) 365-375.

[112] J. Chen, D. Wu, K.C. Tam, K. Pan, Z. Zheng, Effect of surface modification of cellulose nanocrystal on nonisothermal crystallization of poly( $\beta$-hydroxybutyrate) composites, Carbohydr. Polym. 157 (2017) 1821-1829.

[113] L. Carlsson, T. Ingverud, H. Blomberg, A. Carlmark, P.T. Larsson, E. Malmström, Surface characteristics of cellulose nanoparticles grafted by surface-initiated ring-opening polymerization of $\varepsilon$-caprolactone, Cellulose. 22 (2015) 1063-1074.

[114] L. Hou, J. Fang, W. Wang, Z. Xie, D. Dong, N. Zhang, Indocyanine green-functionalized bottle brushes of poly(2-oxazoline) on cellulose nanocrystals for photothermal cancer 
therapy, J. Mater. Chem. B. 5 (2017) 3348-3354.

[115] A.D. Tehrani, E. Neysi, Surface modification of cellulose nanowhisker throughout graft polymerization of 2-ethyl-2-oxazoline, Carbohydr. Polym. 97 (2013) 98-104.

[116] W.A. Braunecker, K. Matyjaszewski, Controlled/living radical polymerization: Features, developments, and perspectives, Prog. Polym. Sci. 32 (2007) 93-146.

[117] J.O. Zoppe, N.C. Ataman, P. Mocny, J. Wang, J. Moraes, H.A. Klok, Surface-Initiated Controlled Radical Polymerization: State-of-the-Art, Opportunities, and Challenges in Surface and Interface Engineering with Polymer Brushes, Chem. Rev. 117 (2017) 11051318.

[118] S. Wohlhauser, G. Delepierre, M. Labet, G. Morandi, W. Thielemans, C. Weder, J.O. Zoppe, Grafting Polymers from Cellulose Nanocrystals: Synthesis, Properties, and Applications, Macromolecules. (2018) acs.macromol.8b00733.

[119] D. Konkolewicz, Y. Wang, M. Zhong, P. Krys, A.A. Isse, A. Gennaro, K. Matyjaszewski, Reversible-deactivation radical polymerization in the presence of metallic copper. A critical assessment of the SARA ATRP and SET-LRP mechanisms, Macromolecules. 46 (2013) 8749-8772.

[120] G. Lligadas, S. Grama, V. Percec, Single-Electron Transfer Living Radical Polymerization Platform to Practice, Develop, and Invent, Biomacromolecules. 18 (2017) 2981-3008.

[121] L. Bai, L. Zhang, Z. Cheng, X. Zhu, Activators generated by electron transfer for atom transfer radical polymerization: Recent advances in catalyst and polymer chemistry, Polym. Chem. 3 (2012) 2685-2697.

[122] A. Carlmark, E. Malmström, Atom Transfer Radical Polymerization from Cellulose Fibers at Ambient Temperature, J. Am. Chem. Soc. 124 (2002) 900-901.

[123] H.-D. Wang, R.D. Roeder, R.A. Whitney, P. Champagne, M.F. Cunningham, Graft Modification of Crystalline Nanocellulose by $\mathrm{Cu}(0)$-mediated SET Living Radical Polymerization, J. Polym. Sci. Part A Polym. Chem. 53 (2015) 2800-2808.

[124] J. Arredondo, P.G. Jessop, P. Champagne, J. Bouchard, M.F. Cunningham, Synthesis of $\mathrm{CO} 2$-responsive cellulose nanocrystals by surface-initiated $\mathrm{Cu}(0)$-mediated polymerisation, Green Chem. 19 (2017) 4141-4152.

[125] J.O. Zoppe, A.V.M. Dupire, T.G.G. Lachat, P. Lemal, L. Rodriguez-Lorenzo, A. PetriFink, C. Weder, H. Klok, Cellulose Nanocrystals with Tethered Polymer Chains: Chemically Patchy versus Uniform Decoration, ACS Macro Lett. (2017) 892-897.

[126] A. Boujemaoui, S. Mongkhontreerat, E. Malmström, A. Carlmark, Preparation and Characterization of Functionalized Cellulose Nanocrystals, Carbohydr. Polym. 115 (2015) 457-464.

[127] F.L. Hatton, S.A. Kedzior, E.D. Cranston, A. Carlmark, Grafting-from Cellulose Nanocrystals via Photoinduced Cu-mediated Reversible-deactivation Radical Polymerization, Carbohydr. Polym. 157 (2017) 1033-1040.

[128] J.O. Zoppe, X. Xu, C. Känel, P. Orsolini, G. Siqueira, P. Tingaut, T. Zimmermann, H.-A. Klok, Effect of Surface Charge on Surface-Initiated Atom Transfer Radical Polymerization from Cellulose Nanocrystals in Aqueous Media, Biomacromolecules. 17 (2016) 1404-1413.

[129] S. Eyley, W. Thielemans, Surface Modification of Cellulose Nanocrystals, Nanoscale. 6 (2014) 7764-7779.

[130] J. Bouchard, M. Méthot, C. Fraschini, S. Beck, Effect of oligosaccharide deposition on the surface of cellulose nanocrystals as a function of acid hydrolysis temperature, Cellulose. 
23 (2016) 3555-3567.

[131] J. Yi, Q. Xu, X. Zhang, H. Zhang, Chiral-Nematic Self-Ordering of Rodlike Cellulose Nanocrystals Grafted with Poly(styrene) in Both Thermotropic and Lyotropic States, Polymer (Guildf). 49 (2008) 4406-4412.

[132] Z. Zhang, K.C. Tam, G. Sèbe, X. Wang, Convenient characterization of polymers grafted on cellulose nanocrystals via SI-ATRP without chain cleavage, Carbohydr. Polym. 199 (2018) 603-609.

[133] J.O. Zoppe, Y. Habibi, O.J. Rojas, R.A. Venditti, L.S. Johansson, K. Efimenko, M. Österberg, J. Laine, Poly(N-isopropylacrylamide) Brushes Grafted from Cellulose Nanocrystals via Surface-Initiated Single-Electron Transfer Living Radical Polymerization, Biomacromolecules. 11 (2010) 2683-2691.

[134] Q. Xu, J. Yi, X. Zhang, H. Zhang, A Novel Amphotropic Polymer Based on Cellulose Nanocrystals Grafted with Azo Polymers, Eur. Polym. J. 44 (2008) 2830-2837.

[135] J. Yu, C. Wang, J. Wang, F. Chu, In Situ Development of Self-reinforced Cellulose Nanocrystals Based Thermoplastic Elastomers by Atom Transfer Radical Polymerization, Carbohydr. Polym. 141 (2016) 143-150.

[136] A. Boujemaoui, C. Cobo Sanchez, J. Engström, C. Bruce, L. Fogelström, A. Carlmark, E. Malmström, Polycaprolactone Nanocomposites Reinforced with Cellulose Nanocrystals Surface-Modified via Covalent Grafting or Physisorption: A Comparative Study, ACS Appl. Mater. Interfaces. 9 (2017) 35305-35318.

[137] Z. Zhang, G. Sèbe, X. Wang, K.C. Tam, UV-Absorbing Cellulose Nanocrystals as Functional Reinforcing Fillers in Poly(vinyl chloride) Films, ACS Appl. Nano Mater. 1 (2018) 632-641.

[138] J. Majoinen, A. Walther, J.R. McKee, E. Kontturi, V. Aseyev, J.M. Malho, J. Ruokolainen, O. Ikkala, Polyelectrolyte Brushes Grafted from Cellulose Nanocrystals using Cu-mediated Surface-Initiated Controlled Radical Polymerization, Biomacromolecules. 12 (2011) 2997-3006.

[139] U.D. Hemraz, K.A. Campbell, J.S. Burdick, K. Ckless, Y. Boluk, R. Sunasee, Cationic Poly(2-aminoethylmethacrylate) and Poly(N-(2-aminoethylmethacrylamide) Modified Cellulose Nanocrystals: Synthesis, Characterization, and Cytotoxicity, Biomacromolecules. 16 (2015) 319-325.

[140] W. Wu, F. Huang, S. Pan, W. Mu, X. Meng, H. Yang, Z. Xu, A.J. Ragauskas, Y. Deng, Thermo-Responsive and Fluorescent Cellulose Nanocrystals Grafted with Polymer Brushes, J. Mater. Chem. A. 3 (2015) 1995-2005.

[141] Z. Zhang, G. Sèbe, X. Wang, K.C. Tam, Gold nanoparticles stabilized by poly(4vinylpyridine) grafted cellulose nanocrystals as efficient and recyclable catalysts, Carbohydr. Polym. 182 (2018) 61-68.

[142] M. Morits, V. Hynninen, Nonappa, A. Niederberger, O. Ikkala, A.H. Gröschel, M. Müllner, Polymer brush guided templating on well-defined rod-like cellulose nanocrystals, Polym. Chem. 9 (2018) 1650-1657.

[143] N. Grishkewich, S.P. Akhlaghi, Y. Zhaoling, R. Berry, K.C. Tam, Cellulose nanocrystalpoly(oligo(ethylene glycol) methacrylate) brushes with tunable LCSTs, Carbohydr. Polym. 144 (2016) 215-222.

[144] J. Yi, Q. Xu, X. Zhang, H. Zhang, Temperature-Induced Chiral Nematic Phase Changes of Suspensions of Poly(N,N-dimethylaminoethyl methacrylate)-Grafted Cellulose Nanocrystals, Cellulose. 16 (2009) 989-997. 
[145] H. Rosilo, J.R. McKee, E. Kontturi, T. Koho, V.P. Hytönen, O. Ikkala, M.A. Kostiainen, Cationic Polymer Brush-Modified Cellulose Nanocrystals for High-Affinity Virus Binding, Nanoscale. 6 (2014) 11871-11881.

[146] U.D. Hemraz, A. Lu, R. Sunasee, Y. Boluk, Structure of Poly(N-isopropylacrylamide) Brushes and Steric Stability of Their Grafted Cellulose Nanocrystal Dispersions, J. Colloid Interface Sci. 430 (2014) 157-165.

[147] J. Zhang, Q. Wu, M.C. Li, K. Song, X. Sun, S.Y. Lee, T. Lei, Thermoresponsive Copolymer Poly(N-Vinylcaprolactam) Grafted Cellulose Nanocrystals: Synthesis, Structure, and Properties, ACS Sustain. Chem. Eng. 5 (2017) 7439-7447.

[148] X. Zhang, J. Zhang, L. Dong, S. Ren, Q. Wu, T. Lei, Thermoresponsive poly(poly(ethylene glycol) methylacrylate)s grafted cellulose nanocrystals through SIATRP polymerization, Cellulose. 24 (2017) 4189-4203.

[149] Y. Yin, X. Tian, X. Jiang, H. Wang, W. Gao, Modification of Cellulose Nanocrystal via SI-ATRP of Styrene and the Mechanism of its Reinforcement of Polymethylmethacrylate, Carbohydr. Polym. 142 (2016) 206-212.

[150] E. Zeinali, V. Haddadi-Asl, H. Roghani-Mamaqani, Nanocrystalline cellulose grafted random copolymers of $\mathrm{N}$ - isopropylacrylamide and acrylic acid synthesized by RAFT polymerization: Effect of different acrylic acid contents on LCST behavior, RSC Adv. 4 (2014) 31428-31442.

[151] E. Zeinali, V. Haddadi-Asl, H. Roghani-Mamaqani, Synthesis of dual thermo- and pHsensitive poly(N-isopropylacrylamide-co-acrylic acid)-grafted cellulose nanocrystals by reversible addition-fragmentation chain transfer polymerization, J. Biomed. Mater. Res. Part A. 106 (2018) 231-243.

[152] A. Anžlovar, M. Huskić, E. Žagar, Modification of nanocrystalline cellulose for application as a reinforcing nanofiller in PMMA composites, Cellulose. 23 (2016) 505518.

[153] A. Boujemaoui, S. Mazières, E. Malmström, M. Destarac, A. Carlmark, SIRAFT/MADIX polymerization of vinyl acetate on cellulose nanocrystals for nanocomposite applications, Polymer (Guildf). 99 (2016) 240-249.

[154] H. Hu, X.J. Hou, X.C. Wang, J.J. Nie, Q. Cai, F.J. Xu, Gold nanoparticle-conjugated heterogeneous polymer brush-wrapped cellulose nanocrystals prepared by combining different controllable polymerization techniques for theranostic applications, Polym. Chem. 7 (2016) 3107-3116.

[155] T. Liu, F. Xue, E. Ding, Cellulose nanocrystals grafted with polyacrylamide assisted by macromolecular RAFT agents, Cellulose. 23 (2016) 3717-3735.

[156] T. Liu, E. Ding, F. Xue, Polyacrylamide and poly(N,N-dimethylacrylamide) grafted cellulose nanocrystals as efficient flocculants for kaolin suspension, Int. J. Biol. Macromol. 103 (2017) 1107-1112.

[157] T. Liu, E. Ding, F. Xue, Grafting poly(N,N-dimethylacrylamide) from cellulose nanocrystals by the macro-RAFT agent-assisted strategy, Cellulose. 25 (2018) 1705-1714.

[158] R. Barbey, L. Lavanant, D. Paripovic, N. Schüwer, C. Sugnaux, S. Tugulu, H. Klok, Polymer Brushes via Surface-Initiated Controlled Radical Polymerization: Synthesis, Characterization, Properties, and Applications, Chem. Rev. 109 (2009) 5437-5527.

[159] R.D. Roeder, O. Garcia-Valdez, R.A. Whitney, P. Champagne, M.F. Cunningham, Graft Modification of Cellulose Nanocrystals via Nitroxide-Mediated Polymerisation, Polym. Chem. 7 (2016) 6383-6390. 
[160] O. Garcia-Valdez, T. Brescacin, J. Arredondo, J. Bouchard, P.G. Jessop, P. Champagne, M.F. Cunningham, Grafting CO2-responsive polymers from cellulose nanocrystals via nitroxide-mediated polymerisation, Polym. Chem. 8 (2017) 4124-4131.

[161] G.M. Dorris, D.G. Gray, The surface analysis of paper and wood fibers by ESCA electron spectroscopy for chemical analysis I. Applications to cellulose and lignin, Cellul. Chem. Technol. 12 (1978) 9-23.

[162] L.S. Johansson, J.M. Campbell, Reproducible XPS on biopolymers: Cellulose studies, Surf. Interface Anal. 36 (2004) 1018-1022.

[163] A.W.T. King, V. Mäkelä, S.A. Kedzior, T. Laaksonen, G.J. Partl, S. Heikkinen, H. Koskela, H.A. Heikkinen, A.J. Holding, E.D. Cranston, I. Kilpeläinen, Liquid-State NMR Analysis of Nanocelluloses, Biomacromolecules. 19 (2018) 2708-2720.

[164] D.L. VanderHart, R.H. Atalla, Studies of microstructure in native celluloses using solidstate carbon-13 NMR, Macromolecules. 17 (1984) 1465-1472.

[165] W.L. Earl, D.L. VanderHart, High Resolution, Magic Angle Sample Spinning 13C NMR of Solid Cellulose I, J. Am. Chem. Soc. 102 (1980) 3251-3252.

[166] L. Heux, E. Dinand, M.R. Vignon, Structural aspects in ultrathin cellulose microfibrils followed by 13C CP-MAS NMR, Carbohydr. Polym. 40 (1999) 115-124.

[167] R.H. Newman, Estimation of the lateral dimensions of cellulose crystallites using 13C NMR signal strengths, Solid State Nucl. Magn. Reson. 15 (1999) 21-29.

[168] S. Montanari, M. Roumani, L. Heux, M.R. Vignon, Topochemistry of carboxylated cellulose nanocrystals resulting from TEMPO-mediated oxidation, Macromolecules. 38 (2005) 1665-1671.

[169] S.X. Peng, H. Chang, S. Kumar, R.J. Moon, J.P. Youngblood, A comparative guide to controlled hydrophobization of cellulose nanocrystals via surface esterification, Cellulose. 23 (2016) 1-22.

[170] S. Gårdebjer, A. Bergstrand, A. Idström, C. Börstell, S. Naana, L. Nordstierna, A. Larsson, Solid-state NMR to quantify surface coverage and chain length of lactic acid modified cellulose nanocrystals, used as fillers in biodegradable composites, Compos. Sci. Technol. 107 (2015) 1-9.

[171] M. Roman, W.T. Winter, Effect of sulfate groups from sulfuric acid hydrolysis on the thermal degradation behavior of bacterial cellulose, Biomacromolecules. 5 (2004) 16711677.

[172] C.A. Angell, K.L. Ngai, G.B. McKenna, P.F. McMillan, S.W. Martin, Relaxation in glassforming liquids and amorphous solids, J. Appl. Phys. 88 (2000) 3113-3157.

[173] J. Wang, G. Siqueira, G. Müller, D. Rentsch, A. Huch, P. Tingaut, J. LevaloisGrützmacher, H. Grützmacher, Synthesis of new bis(acyl)phosphane oxide photoinitiators for the surface functionalization of cellulose nanocrystals, Chem. Commun. 52 (2016) 2823-2826.

[174] W.Y. Hamad, C. Miao, NANOCOMPOSITE BIOMATERIALS OF NANOCRYSTALLINE CELLULOSE (NCC) AND POLYLACTIC ACID (PLA), US 2011/0196094 A1, 2011.

[175] Y. Hamad, Wadood, S. Su, THERMOPLASTIC NANOCOMPOSITE MATERIAL BASED ON NANOCRYSTALLINE CELLULOSE (NCC), US 8,349,948 B2, 2013.

[176] W. Hamad, S. Su, NCC-BASED SUPRAMOLECULAR MATERIALS FOR THERMOPLASTIC AND THERMOSET POLYMER COMPOSITES, WO 2013/037041 A1, 2013. 
[177] A. Carlmark Malkoch, E. Malmstrom Jonsson, A. Boujemaoui, FUNCTIONALIZED CELLULOSE NANOCRYSTALS, A METHOD FOR THE PREPARATION THEREOF AND USE OF FUNCTIONALIZED CELLULOSE NANOCRYSTALS IN COMPOSITES AND FOR GRAFTING, WO 2014/070092 A1, 2014.

[178] D.J. Castro, R. Karnati, S.M. Wilson, W. Cheng, M. Liu, Z. Zhang, USE OF NANOCRYSTALINE CELLULOSE AND POLYMER GRAFTED NANOCRYSTALINE CELLULOSE FOR INCREASING RETENTION, WET STRENGTH, AND DRY STRENGTH IN PAPERMAKNG PROCESS, WO 2015/050806 A1, 2014.

[179] S. Moghadam, R. Karnati, H. Mode, NANOCRYSTALLINE CELLULOSE AND POLYMER-GRAFTED NANOCRYSTALLINE CELLULOSE AS RHEOLOGY MODIFYING AGENTS FOR MAGNESIUM OXIDE AND LIME SLURRIES, WO 2017/066540 A1, 2017. 